\title{
HETEROGENEIDADE ESPACIAL DE ATRIBUTOS DO SOLO EM ÁREAS SOB MANEJO ROTACIONADO DE CAPIM-ELEFANTE (Pennisetum purpureum Schum.)
}

\section{SILVIA DEL CARMEN IMHOFF}

Engenheiro Agrônomo

Orientador: Prof. Dr. ÁLVARO PIRES DA SILVA

\author{
Dissertação apresentada à Escola Superior de \\ Agricultura "Luiz de Queiroz", Universidade de São \\ Paulo, para obtenção do título de Mestre em \\ Agronomia, Área de Concentração: Solos e \\ Nutrição de Plantas.
}

\author{
PIRACICABA \\ Estado de São Paulo - Brasil \\ Maio - 1998
}


Dados Internacionais de Catalogação na Publiçą̧ão (CIP)

DIVISĀO DE BIBLIOTECA E DOCUMENTAÇĀO - Campus "Lữz de Queiroz"/USP

\section{Imhoff, Silvia del Carmen}

Heterogeneidadë espacial de atributos do solo em áreas sob manejo rotacionado de capim elefante (Pennisetum purpureum Schum.) / Silvia del Carmen Imhoff. - -

Piracicaba, 1998.

55 p. : il.

Dissertação (mestrado) - Escola Superior de Agricultura Luiz de Queiroz, 1998.

Bibliografia.

1. Capim elefante 2. Distribuição espacial 3. Pastejo rotacionado 4. Propriedade fisico-quimica do solo I. Título 


\section{AGRADECIMENTOS}

Ao Professor Álvaro Pires da Silva pelo incentivo constante, confiança e ensinamentos oferecidos durante todo o curso, e pela valiosa contribuição no desenvolvimento deste trabalho.

Ao colega Cássio A. Tormena pela amizade, sugestões e contribuição na execução deste trabalho.

Aos companheiros de pós-graduação pela amizade e colaboração para a realização deste trabalho: Vládia Correchel, Maria del Carmen Ferragine, Pablo Ghiberto e Carlos Giaveno.

Aos funcionários do Laboratório de Física de Solos Wladimir J. Rosignolo e Luciano Dias Ferraz, pelo auxílio na determinação de parte das análises físicas.

Á Coordenação do Curso de Pós-Graduação em Solos e Nutrição de Plantas da ESALQ, pela oportunidade da realização do Curso.

Á Universidade Nacional do Litoral (Argentina) pela concessão da bolsa de estudo, e às autoridades da Faculdade de Ciências Agrarias de Esperanza pela liberação para a realização do Curso.

Aos colegas Professores Maria A. Toniutti, Daniel Grenón, Hugo Micheloud, Jorge de Orellana e Miguel Pilatti, pelo estímulo e apoio oferecido para a realização do Curso.

A Linda Monica Premazzi e Miguel Cooper pelo apoio e amizade.

A todos que, direta ou indiretamente, contribuíram para a concretização deste trabalho. 


\section{SUMÁRIO}

Página

LISTA DE FIGURAS …......................................................... iv

LISTA DE TABELAS ….......................................................

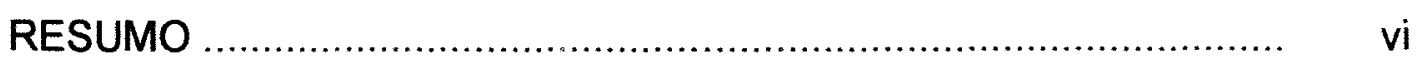

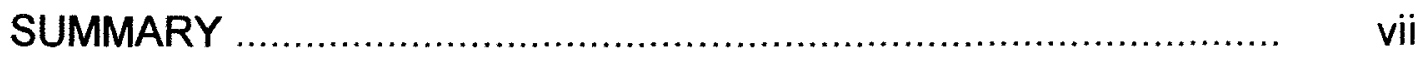

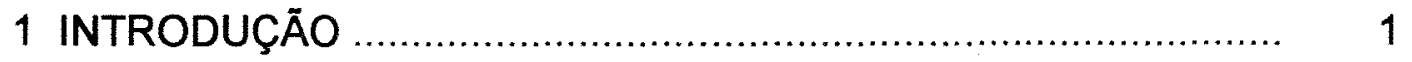

2 REVISÃO DE LITERATURA …............................................. 4

3 MATERIAL E MÉTODOS ..................................................... 20

3.1 Caracterização da área e do solo .......................................... 20

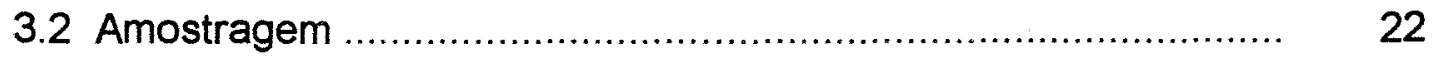

3.3 Determinações ................................................................... 22

4 RESULTADOS E DISCUSSÃO ….............................................. 27

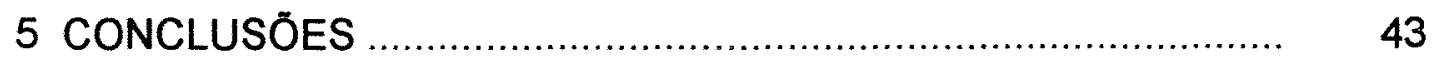

REFERÊNCIAS BIBLIOGRÁFICAS ...................................... 44 


\section{LISTA DE FIGURAS}

Página

1 Esquema de coleta de amostras com estrutura indeformada e

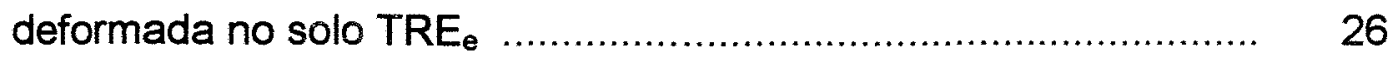

2 Coordenadas dos pontos de amostragem ................................... 26

3 Freqüência acumulada do peso dos agregados em função do seu tamanho para as posições espaciais debaixo das touceiras e entre as touceiras

4 Representação tridimensional dos valores de resistência à penetração, debaixo das touceiras e entre as touceiras, no sistema de pastejo rotacionado intensivo 


\section{LISTA DE TABELAS}

Página

1 Momentos estatísticos dos atributos químicos do solo nas posições DT e ET

2 Niveis de significância associados aos testes de comparação de médias (teste $\mathrm{t}$ ) e de variâncias (teste $\mathrm{F}$ ), para as variáveis analisadas

3 Valores médios e nível de significância para os parâmetros físicos do solo utilizados no modelo de distribuição do tamanho dos agregados secos

4 Resultados da análise de regressão da curva de resistência à penetração 


\title{
HETEROGENEIDADE ESPACIAL DE ATRIBUTOS DO SOLO EM ÁREAS SOB MANEJO ROTACIONADO DE CAPIM-ELEFANTE
} (Pennisetum purpureum Schum.)

\author{
Autora: SILVIA DEL CARMEN IMHOFF \\ Orientador: Prof. Dr. ÁLVARO PIRES DA SILVA
}

\section{RESUMO}

O pisoteio do solo pelos animais pode promover alteraçōes significativas nos atributos do solo. A identificação da heterogeneidade espacial desses atributos depende da escala de amostragem. Esse estudo foi desenvolvido para testar a hipótese de que os atributos químicos e físicos do solo debaixo das plantas de capim-elefante diferem daqueles entre as plantas. A pesquisa foi conduzida num solo classificado como Terra Roxa Estruturada eutrófico. Foram retiradas 48 amostras na camada de $0-10 \mathrm{~cm}$ (24 debaixo das plantas e 24 entre as plantas), determinando-se $\mathrm{pH}$, matéria orgânica, $\mathrm{P}$ disponível, $\mathrm{K}, \mathrm{Ca}$ e Mg trocáveis, S, SB, CTC, V\%, distribuição do tamanho dos agregados, densidade do solo e resistência à penetração. $A$ análise estatística (teste $\mathrm{t}$ ) demonstrou que não existem diferenças significativas nos atributos químicos do solo em relação à posição espacial. Diferenças estatísticas significativas foram determinadas para as propriedades físicas. A dispersão dos agregados, a densidade do solo e a resistência mecânica foram mais elevadas entre as plantas que debaixo das touceiras. 


\title{
SPATIAL HETEROGENEITY OF SOIL ATTRIBUTES IN AREAS UNDER ROTATIONAL MANAGEMENT OF ELEPHANT-GRASS (Pennisetum purpureum Schum.)
}

\author{
Author: SILVIA DEL CARMEN IMHOFF \\ Adviser: Prof. Dr. ÁLVARO PIRES DA SILVA
}

\section{SUMMARY}

The trampling of the soil by animals can promote significant alterations on the soil attributes. The pattern of the space heterogeneity of those attributes depends on the scale. This study was carried out to test the hypothesis that the physical and chemical attributes of the soil under the plants of elephant grass differ from those between the plants. The research was conducted in a Kandiudalfic Eutrudox. Forty-eight samples were taken at the 0$10 \mathrm{~cm}$ depth (24 under the plants and 24 between the plants). The samples were analyzed for $\mathrm{pH}$, organic matter content, available $\mathrm{P}$, exchangable $\mathrm{K}, \mathrm{Ca}$ and Mg, S, CEC, V\%, dry aggregate size distribution, bulk density, and soil resistance to penetration. The statistical analysis ( $t$ test) indicated that there were no significant differences between the positions regarding the chemical attributes. Conversely there was a significant difference with respect to the soil physical properties. The variability the soil aggregates, bulk density, and the mechanical resistance of the soil were higher between the plants than under the plants. 


\section{INTRODUÇÃO}

O Brasil apresenta condições climáticas muito propícias à produção animal a partir de sistemas sob pastejo. As pastagens ocupam cerca de $76 \%$ da superfície utilizada pela agricultura, o que corresponde a $20 \%$ da área total do pais.

A área coberta com forrageiras estendeu-se rapidamente nas últimas duas décadas. Essa expansão resultou da abertura de novas áreas agrícolas nas regiões dos Cerrados e da Floresta Amazônica. Entretanto, a degradação das pastagens é, na atualidade, um dos problemas da pecuária brasileira que mais afeta a sustentabilidade dos sistemas pecuários.

A produção animal, que utiliza como base de alimentação as pastagens, deve ser compreendida como ecossistemas complexos nos quais as condições do clima, solo, animal e produtividade potencial desejada determinam a espécie ou cultivar mais indicado para cada situação.

O capim-elefante é uma das espécies de maior potencial de produção dentre as forrageiras tropicais e subtropicais. Produções de 80 a $90 \mathrm{Mg}$ de matéria seca por hectare podem ser obtidas anualmente, sempre que sejam utilizadas práticas de manejo e de adubação adequadas à espécie vegetal. Por essa razão é considerada uma cultura muito exigente em termos de fertilidade do solo.

A fertilidade do solo pode ser definida como a capacidade do solo de fornecer água, oxigênio, calor e nutrientes em quantidades e formas adequadas ao crescimento vegetal. Isso implica na ausência de limitações ao 
desenvolvimento das raízes, tais como elevadas concentrações de elementos tóxicos na solução do solo ou presença de camadas compactadas.

Em sistemas pecuários o pisoteio do solo pelos animais pode exercer uma influência muito grande no ambiente radicular. $O$ tráfego dos animais pode promover alterações significativas nos atributos físicos do solo com reflexo nas suas propriedades químicas e biológicas. A degradação da estrutura do solo, devido à compactação pelo pisoteio, é um dos efeitos mais freqüentemente observado nas áreas pastejadas. A perda da qualidade física do solo pode reduzir a produtividade das pastagens, mesmo com disponibilidade adequada de nutrientes.

As plantas, por sua vez, possuem capacidade para modificar a rizosfera. Através da absorção e liberação de substâncias inorgânicas, e da ação na agregação do solo, as raizes alteram as condições físico-químicas da interface solo-raiz, contribuindo para a variabilidade espacial e temporal dos atributos do solo.

A heterogeneidade nos atributos do solo é uma característica inerente aos ecossistemas, porém o seu reconhecimento depende da escala espacial utilizada na realização das pesquisas. A identificação da variabilidade das propriedades do solo, a nível detalhado, é importante quando se pretende aumentar a eficiência de produção das pastagens visando otimizar a produtividade do sistema pecuário.

A hipótese de que os atributos físicos e químicos do solo sob as plantas diferem daqueles entre as plantas orientou o desenvolvimento deste trabalho.

O objetivo geral deste trabalho foi o de caracterizar a heterogeneidade de atributos físicos e químicos do solo associados com a posição espacial sob e entre as plantas de capim-elefante (Pennisetum purpureum Schum.), em um sistema de pastejo rotacionado intensivo, utilizado há vinte e sete anos. 
Os objetivos específicos foram: (I) avaliar algumas propriedades fisicas e químicas do solo sob e entre as plantas; (II) determinar se existem diferenças dessas propriedades em relação à posição espacial. 


\section{REVISÃO DE LITERATURA}

A produtividade de ecossistemas de pastagens é determinada pelos fatores de produção clima - solo - planta - animal - manejo. Esses fatores estão interrelacionados, razão pela qual uma modificação em qualquer um deles pode afetar a produtividade do ecossistema.

No Brasil, na maioria das regiōes de pecuária, as condições climáticas (chuva, temperatura, luz) variam com as estações do ano, sendo responsáveis pela estacionalidade de produção das forrageiras (Rolim, 1986). Contudo, as gramineas tropicais apresentam 0 metabolismo $\mathrm{C}_{4}$ de fotossintese, o qual possibilita produções mais elevadas que as observadas para as espécies de clima temperado (Rodrigues \& Rodrigues, 1987). O fator animal, devido aos progressos genéticos alcançados, também não é limitante (Aguiar, 1997). Essas características especificas determinam que a espécie vegetal, o tipo de solo e o manejo constituam-se nos fatores chaves para elevar a eficiência dos sistemas pecuários.

Dentre todas as plantas forrageiras tropicais, o capim-elefante é considerado a espécie de maior potencial de produção (Santos, 1993). Silva et al. (1996) e Faria et al. (1996) assinalaram que na literatura são encontradas produçōes de $80-90 \mathrm{Mg}$ de matéria seca por hectare por ano, quando são otimizados todos os fatores que determinam a produtividade dessa espécie. No Brasil foram medidas produções de $20-30 \mathrm{Mg}$ de matéria seca por hectare para a época de máxima produção da espécie (primavera - verão ) (Hillesheim,1987; Balsalobre, 1996). 
O manejo eficiente da pastagem exige a escolha de um sistema de pastejo que permita maximizar a produção animal sem afetar a persistência das plantas forrageiras. O sistema de pastejo é definido como a combinação integrada do animal, da planta, do solo e de outros componentes do ambiente e métodos de pastejo pelos quais o sistema é manejado para atingir objetivos específicos (Rodrigues \& Reis, 1997). Assim, a longevidade de uma pastagem depende de fatores ligados ao clima da região, ao tipo de animal, à taxa de lotação, à espécie vegetal e à fertilidade do solo (Corsi \& Martha Júnior, 1997; Kichel et al., 1997).

Nas regiões tropicais e subtropicais há uma tendência de diminuição da taxa de expansão dos pastos cultivados e/ou queda de produtividade após alguns anos de seu estabelecimento (Gijsman \& Thomas, 1996). Essa queda é atribuída, em geral, à degradação das propriedades químicas do solo. Segundo Aguiar (1997) a baixa fertilidade natural dos solos é uma das maiores limitações para a produção das forrageiras. Raij et al. (1996) estabeleceram classes de teores para os macro e micronutrientes no solo, e sugeriram niveis a partir dos quais devem ser feitas adubações para as forrageiras. Entretanto, alterações nas propriedades físicas do solo também podem exercer uma grande influência na produtividade das pastagens.

A qualidade do ambiente radicular é determinada pela presença de condições fisicas não impeditivas ao crescimento das plantas, bem como pela disponibilidade de nutrientes e/ou ausência de elementos tóxicos (Russell, 1977). Os fatores físicos que afetam diretamente $o$ crescimento e $O$ desenvolvimento das plantas são a temperatura, o conteúdo de água, a aeração e a resistência mecânica do solo (Letey, 1985).

O crescimento das raízes pode ser limitado por baixas ou altas temperaturas do solo. A origem da espécie (clima tropical ou temperado) condiciona a temperatura ótima de desenvolvimento (Marschner, 1995). A temperatura do solo afeta todos os processos metabólicos, tanto das plantas 
quanto dos microrganismos do solo. Dessa forma, a temperatura do solo condiciona a profundidade de enraizamento, a quantidade de raízes laterais formadas e o ângulo de crescimento relativo ao eixo principal. Dois processos importantes são regulados pela temperatura do solo: a taxa de absorção de água e a taxa de absorção de íons, influenciando indiretamente a disponibilidade de nutrientes para as plantas.

As raizes crescem devido a formação de novas camadas de células na região meristemática e, principalmente, através da elongação das células que estão situadas acima dessa região. Para o processo acontecer, o potencial da água dentro das células deve ser menor que o potencial água do solo, de modo a se manter o fluxo de água do solo para a raiz. A presença de água disponivel no solo é, portanto, imprescindivel para o desenvolvimento radicular. O armazenamento de água no solo depende de vários atributos, tais como a estrutura, a textura, o teor de matéria orgânica e a porosidade do solo. Este último fator influencia diretamente o crescimento das plantas ao determinar o fluxo de ar no solo.

As plantas obtêm a energia que precisam para seu adequado funcionamento bioquímico, principalmente, através de processos de oxidação. Assim, quantidades suficientes de oxigênio devem estar presentes no solo. $O$ movimento do oxigênio ocorre no espaço poroso do solo e através do filme de água que recobre as raizes. Vários autores assinalam, em geral, que as raizes tem limitado o seu crescimento quando a porosidade de aeração é inferior a 10\% (Dexter, 1988; Glinski \& Lipiec, 1990; Marshall et al., 1996; Rendig \& Taylor, 1989; Tardieu, 1994).

O sistema poroso e a distribuição do tamanho dos poros depende da estrutura do solo. A estrutura é definida como a expressão atual do arranjo das partículas primárias (areia, silte e argila) e secundárias do solo (agregados) (Gupta et al., 1989; Marshall et al., 1996). A estrutura do solo pode ser descrita a nivel macroscópico e microscópico. No primeiro caso, é caraterizada pela 
densidade do solo, porosidade total e relação de vazios, e no nível microscópico através de medidas de fluxo de água, ar e resistência do solo (Gupta et al., 1989).

As raizes crescem nos macroporos contínuos ou fissuras que existem dentro e entre os agregados do solo, sempre que eles apresentem um tamanho igual o maior ao diâmetro da ponta da raiz, ou exercendo pressão contra as partículas do solo. A pressão exercida pelas raízes para deformar o solo pode produzir o deslocamento das partículas elou agregados. Neste último caso, o impedimento mecânico do solo deve ser menor do que a pressão exercida pela raiz (Hadas, 1997).

O termo impedimento mecânico refere à resistência oferecida pela matriz do solo à deformação produzida pelas raízes. Estas produzem dois tipos de compressão do solo: esférica, causada pela pressão axial exercida pela ponta da raiz, e cilíndrica, sendo esta última produzida pela pressão radial gerada pela expansão da parte da raiz que cresce acima da coifa. Em geral se aceita que as raízes têm limitado o crescimento quando a resistência mecânica do solo é maior que 2-3 MPa, valor que varia segundo a espécie e as condições do ambiente radicular (Atwell, 1993; Glinski \& Lipiec, 1990; Gupta \& Allmaras, 1987; Semmel et al., 1990; Taylor \& Burnett, 1964; Vepraskas, 1994).

Para determinar a resistência do solo à penetração das raízes são utilizados instrumentos denominados penetrômetros, sendo as suas medições associadas à força exercida pelas raizes ao crescer (Bengough, 1991; Bengough et al., 1997; Bennie, 1991; Hettiaratchi, 1992).

Para um adequado crescimento, as plantas precisam uma estrutura do solo que possibilite uma grande área de contato entre as raízes e o solo, com suficiente espaço poroso contínuo para o fluxo de água e ar e reduzida resistência do solo à penetração das raízes (Silva et al., 1997a). A função das raízes na formação da estrutura consiste na agregação do solo. As raízes e pêlos radiculares, ao crescerem, produzem linhas de fraqueza mecânica no 
solo, as quais podem se fraturar e formar agregados. Também a pressão por elas exercida, em solos deformáveis, leva à formação de agregados ao favorecer o contato entre as partículas. Os exudados radiculares podem ajudar a flocular os coloides do solo e, dessa forma, auxiliar na estabilização dos agregados. Além disso, as raízes ao absorverem água do solo causam desidratação da rizosfera, a qual resulta numa contração do solo. Esse processo favorece a cimentação das partículas. O padrão de ruptura do solo, por secamento, corresponde a polígonos irregulares, mas pode ser alterado pelas raízes. Assim, as pastagens produzem um padrão circular, sendo classificada essa forma dos agregados como granular (Glinski \& Lipiec, 1990; Marshall et al., 1996).

A formação de agregados estáveis e de diâmetro pequeno é favorecida pela ocorrência de múltiplos ciclos de umidecimento e secamento do solo. Nessas condições, o solo apresenta um sistema poroso heterogêneo, com poros grandes entre os agregados de modo a permitir uma aeração adequada do solo e poros pequenos contínuos dentro dos agregados, os quais facilitam o movimento da água e dos ions no solo (Glinski \& Lipiec, 1990; Goss, 1987; Horn et al., 1994; Semmel et al., 1990). O tamanho mais adequado dos agregados varia com a textura do solo, umidade e capacidade da espécie vegetal para atravessá-los. Assim, tamanhos dos agregados que variam entre $1 \mathrm{~mm}$ e $4 \mathrm{~mm}$ de diâmetro parecem ser os mais convenientes para o fluxo de água e ions, sempre que não existam limitações de aeração (Braunack \& Dexter, 1989a; Braunack \& Dexter, 1989b; Donald et al., 1987; Passioura, 1991; Vepraskas, 1994).

Segundo Tisdall \& Oades (1982) o tamanho dos agregados é condicionado pelo tipo de substâncias orgânicas que atua como agente de união das partículas do solo para formar micro e macroagregados. Essas substâncias, segundo sua composição, foram classificadas como: transitórias, temporárias e persistentes. O grupo de agentes transitórios é formado por polissacarideos produzidos pelos microrganismos do solo quando são 
incorporados produtos orgânicos, por exemplo estercos. Essas substâncias são formadas e decompostas rapidamente, e estão associadas com a formação de agregados grandes, os quais não são muito estáveis. Os agentes temporários são os resíduos vegetais, as raizes e fungos, os quais se consideram relacionados à formação de macroagregados. Os agentes persistentes são constituídos pela matéria orgânica do solo fortemente transformada (humificada), a qual atua diretamente na formação dos microagregados estáveis do solo.

Braunack \& Dexter (1989b) determinaram o tamanho de agregados ótimo para vários atributos físicos do solo. Concluiram que agregados com diâmetro menor de $0,5 \mathrm{~mm}$ ou com diâmetro maior de $8 \mathrm{~mm}$ podem limitar o desenvolvimento das culturas, ao afetar a capacidade de armazenamento de água do solo, a aeração e a resistência mecânica à penetração das raízes.

As raizes podem obter os nutrientes que precisam para seu crescimento através de três mecanismos: intercepção radicular, difusão e fluxo de massa. A importância de um ou outro mecanismo depende de como os nutrientes se movimentam no solo e são absorvidos pelas plantas. Assim, o fluxo de massa fornece principalmente cálcio, magnésio, enxofre, e nitrogênio, enquanto o processo de difusão provê mais potássio e fósforo para as raizes (Barber, 1984; Lipiec \& Stepniewski, 1995; Marschner, 1995). As plantas, ao absorverem íons de forma diferenciada, podem gerar uma área de menor concentração ou de acúmulo de nutrientes ao redor das raízes. A concentração de cada nutriente na rizosfera poderá ser menor, maior ou semelhante aquela existente na massa do solo dependendo de sua concentração na solução do solo, taxa de movimentação do solo para as raízes e taxa de consumo destas. A liberação dos íons hidrogênio e bicarbonato, e de exudados orgânicos produzem modificações no $\mathrm{pH}$ da rizosfera. O consumo de oxigênio e a liberação de dióxido de carbono alteram o potencial redox. Estas modificações afetam tanto a solubilidade dos nutrientes quanto a atividade biológica no solo. $O$ resultado, freqüentemente observado, é que as propriedades químicas do 
solo na rizosfera diferem daquelas situadas a uma certa distância das plantas (Goss, 1987; Marschner, 1995; Robinson, 1994). Esta situação também se verifica para as propriedades físicas do solo, principalmente quando a estrutura do solo é alterada.

Quando ocorre a degradação da estrutura do solo devido, por exemplo, ao processo de compactação, observa-se um aumento no impedimento mecânico do solo. Plantas que crescem em um ambiente restritivo possuem, em geral, raizes com menor comprimento e menor taxa de elongação, distribuição irregular no perfil do solo, maior diâmetro e ramificação lateral (Atwell, 1993; Bennie, 1991; Russell, 1977).

As modificações estruturais e o menor comprimento das raizes determinam, em geral, uma menor disponibilidade dos nutrientes pouco móveis no solo. Por sua vez, esses órgãos apresentam requerimentos de oxigênio e nutrientes superiores aos de raízes que crescem em condições não restritivas, devido ao maior gasto energético para a manutenção das diversas estruturas da planta. No entanto, alguns trabalhos tem demonstrado que niveis moderados de compactação podem aumentar a eficiência do uso da água ao incrementar a condutividade não saturada do solo e melhorar o contato solo-raiz (Glinski \& Lipiec, 1990), bem como aumentar a disponibilidade dos íns que se movimentam por difusão (Hoffman \& Jungk, 1995; Shierlaw \& Alston, 1984). Estes processos parecem ser mais relevantes em solos de textura fina e em anos secos (Vepraskas, 1994).

Boone \& Veen (1994) assinalaram que o transporte de água $e$ nutrientes e sua absorção pelas plantas é favorecido ao aumentar o contato solo-raiz, enquanto que o transporte e consumo de oxigênio é prejudicado. Esses processos ocorrem simultaneamente, o qual indica a complexidade do ambiente radicular. As variadas interações que nele ocorrem determinam o crescimento e produtividade das plantas. Uma das conseqüencias dessas interações é a heterogeneidade horizontal e vertical dos atributos do solo. 
As plantas possuem diversos mecanismos para explorar a variabilidade espacial. Contudo, a identificação da heterogeneidade espacial das propriedades físico-químicas é importante para identificar os locais de menor fertilidade, e através de práticas corretivas adequadas aumentar a eficiência dos sistemas de manejo, possibilitando a obtenção de máximos rendimentos, uma vez que há diferenças entre as espécies no que conceme a sua capacidade para desenvolver seu sistema radicular em microsítios férteis (Jackson \& Caldwell, 1989; Jackson \& Caldwell ,1993).

$\mathrm{Na}$ literatura, os trabalhos sobre os efeitos das plantas em aspectos da fertilidade do solo podem ser separados em dois grupos: os que estudam as relações entre conteúdo de nutrientes no tecido vegetal e teores no solo e aqueles que analisam as propriedades do solo em relação a cobertura vegetal. A heterogeneidade do solo, gerada pelas plantas, foi estudada para diversas espécies, principalmente arbóreas perenes. Nesses trabalhos foram comparados os atributos químicos do solo em duas posições espaciais: uma correspondeu à projeção da copa e, a outra ao espaço entre as plantas. Os resultados mostraram a presença de "ilhas de fertilidade" química, as quais coincidiram com a projeção da copa, local com maior concentração de raízes.

A expressão "ilhas de fertilidade" é utilizada para indicar áreas de maior concentração de nutrientes no solo, as quais estão associadas à presença do sistema radicular de plantas individuais. Dessa forma, o teor dos nutrientes na rizosfera é maior que o teor na proximidade da rizosfera. Essas ilhas parecem resultar do acúmulo de nutrientes produzido pela atividade biológica e processos físicos induzidos pelas raizes (Schlesinger et al., 1990).

Schlesinger et al. (1996) estudaram a distribuição espacial de nutrientes em ecossistemas de regiões áridas e semi-áridas. Esses autores assinalaram que as pastagens também são capazes de acumular nutrientes ao redor das plantas, e que a heterogeneidade induzida pelas forrageiras perenes ocorreu a nivel de microescala (distância menor de $20 \mathrm{~cm}$ ). 
O aumento nos conteúdos de carbono orgânico e nitrogênio debaixo de plantas forrageiras cespitosas também foi demostrado por Hook et al. (1991), Kelly et al. (1996) e Vinton \& Burke (1995). Kelly \& Burke (1997) demonstraram que as áreas enriquecidas do solo, situadas debaixo das plantas, fornecem nutrientes durante um tempo breve depois que as plantas morrem. Esse tempo é determinado pela taxa de reciclagem dos resíduos vegetais. A taxa de mineralização desses resíduos e da matéria orgânica do solo depende de uma série de fatores, tais como a temperatura, a umidade, a textura e a disponibilidade de nitrogênio do solo.

A quantidade de nitrogênio disponivel no solo é determinada tanto pelo volume de matéria seca incorporada na forma de resíduos vegetais e animais, quanto pela sua qualidade. Balsalobre (1996), numa pesquisa desenvolvida na área com pastagem de capim-elefante na ESALQ (a mesma deste estudo), determinou que a matéria seca produzida pela forrageira foi de $23,59 \mathrm{Mg} \mathrm{MS} \mathrm{ha}{ }^{-1}$ para o período de máxima produção (outubro-abril) com $22 \%$ de perdas de forragem motivadas pelo pastejo. Hillesheim (1987) indicou que as perdas, para a mesma espécie vegetal e local, variaram de 15 a $26 \%$ do total de forragem disponivel. Por sua vez, a qualidade dos residuos é condicionada, principalmente, pela relação lignina/nitrogênio do material (Burke et al., 1997). Rodrigues (1993) mencionou que $70 \%$ do nitrogênio incorporado com os resíduos vegetais é imobilizado pelos microrganismos e resulta estabilizado no solo ao passar a formar parte do "pool" de matéria orgânica do solo quando os microrganismos morrem, ficando protegido pela matriz do solo. Esse efeito de proteção já foi observado por Tisdall \& Oades (1982), Oades (1984) e Degens (1997). Estes autores assinalaram que os compostos orgânicos podem ficar retidos dentro de microagregados bem como em poros pequenos do solo, e dessa forma contribuem para aumentar o teor de carbono do solo.

As forrageiras $\mathrm{C}_{4}$ se caracterizam por possuir alto potencial de produção, mas com teores baixos de nitrogênio na biomassa, razões pelas quais o processo de acúmulo de carbono no solo é favorecido, principalmente 
em solos de textura argilosa (Epstein et al., 1997). Esse acúmulo varia, portanto, em função da quantidade e qualidade do material orgânico depositado ao redor das plantas, o qual depende da intensidade do pastejo (Derner et al., 1997). O sistema de manejo da pastagem influencia diretamente a intensidade de pastejo, por esse motivo é considerado um dos fatores que determina o conteúdo e a distribuição dos nutrientes no solo (Manley et al.,1995). Estes autores demonstraram que em pastagens de 11 anos, sob sistemas de pastejo rotacionado intensivo, houve um incremento na quantidade de carbono $e$ nitrogênio transportados para a parte aérea das plantas, resultando numa maior produção da parte aérea e menor produção de biomassa radicular. No entanto assinalaram que, devido à taxa elevada de reciclagem dos nutrientes, o pastejo durante 11 anos não alterou negativamente os teores de carbono e nitrogênio no solo.

Em áreas com pastagens pode ocorrer aumento dos teores de outros nutrientes no solo, tais como nitrogênio, enxofre e fósforo (Haynes \& Williams, 1993), potássio, cálcio e magnésio (Saunders, 1984). Esse efeito depende da lotação animal utilizada no sistema, uma vez que esta condiciona a reciclagem de nutrientes via fezes e urina. Em sistemas pecuários a maior parte dos nutrientes minerais é retornada ao solo através das excreções. Valores que variam entre 60 e $90 \%$ são mencionados por Haynes \& Williams (1993). Alguns nutrientes são excretados, principalmente, via urina (potássio), enquanto outros como fezes (fósforo, cálcio, magnésio). Nitrogênio e enxofre são retornados em proporções semelhantes pelas duas vias (Haynes \& Williams, 1993; Monteiro \& Werner, 1997).

Os nutrientes que são reciclados via urina são considerados como prontamente disponiveis para as plantas, porém estão mais expostos a perdas por lixiviação, imobilização, volatilização e desnitrificação, dependendo das condiçōes de temperatura e umidade do ambiente. A maior parte daqueles que retornam via fezes se encontram formando parte de compostos orgânicos que são difíceis de degradar (celulose, hemicelulose e lignina). Segundo Rodriguez 
(1993) só $35 \%$ da quantidade de fezes incorporada mineraliza-se no primeiro ano. Portanto, a liberação dos nutrientes contidos nas fezes é mais lenta que via urina, constituindo-se em reserva de nutrientes para as plantas (Corsi \& Martha Júnior, 1997; Haynes \& Williams, 1993; Monteiro \& Werner, 1997). Esses autores concordam em assinalar o efeito positivo da reciclagem de nutrientes das excreções no crescimento das pastagens. No entanto, esse efeito é condicionado pela distribuição das dejeções, as quais se apresentam, geralmente, desigualmente espalhadas nos piquetes (Monteiro \& Werner, 1997). Uma das formas de se obter uma distribuição mais uniforme é empregar sistemas de pastejo intensivos, ou seja alta lotação animal (Haynes \& Williams, 1993). Porém, a intensidade do pastejo determina o pisoteio do solo pelos animais influenciando, dessa forma, nas propriedades físicas do solo.

O pisoteio excessivo ocasiona compactação da camada superficial do solo, produzindo alterações significativas dos atributos físicos do solo. A compactação do solo é gerada pela pressão exercida pelas patas dos animais e, a sua magnitude depende da carga aplicada, a qual está diretamente relacionada ao tamanho dos animais (Villatt \& Pullar, 1983). Estes autores assinalaram que bois da raça Jersey podem exercer pressões de 0,2 MPa, enquanto que as pressões aplicadas no solo por ovinos e caprinos foram de $0,08 \mathrm{MPa}$ e 0,06 $\mathrm{MPa}$, respectivamente. Na literatura são mencionados valores que variam entre $0,30-0,49 \mathrm{MPa}$ para bovinos de $400-500 \mathrm{~kg}$, podendo atingir a profundidade de $7-10 \mathrm{~cm}$ (Carvalho, 1976, Scholefield et al., 1985; Proffitt et al. 1993).

Uma característica dos solos que possuem a sua estrutura degradada é um aumento da compacidade do solo, expressão utilizada para descrever o arranjo apertado das partículas do solo com redução do volume de poros do solo. O termo compactação é empregado para caracterizar a compacidade provocada por forças mecânicas externas (trânsito de máquinas e implementos agrícolas, pisoteio animal), e a expressão adensamento para caracterizar a compacidade produzida por processos naturais (dessecação, iluviação, 
precipitação química) (Rezende, 1997). O termo compressão também é utilizado para indicar o processo que descreve a diminuição do volume do solo sob aplicação de uma carga externa. A compressão de solos saturados é chamada consolidação, enquanto $\circ$ processo em solos não saturados é denominado compactação (Gupta \& Allmaras, 1987; Horn \& Lebert, 1994).

Os solos, quando submetidos a uma certa carga ou pressão, sofrem redução do seu volume em decorrência da deformação e rearranjamento das partículas sólidas. Como conseqüencia observa-se um aumento da densidade do solo, uma diminuição da porosidade, uma alteração do tamanho e continuidade dos poros e um aumento da resistência à penetração radicular (Marshall et al.,1996). O processo de compactação tem, portanto, importantes implicações na dinâmica da água no solo e no crescimento das plantas.

Os mecanismos que controlam as mudanças na matriz do solo durante o processo de compactação são: a) aumento do contato entre os agregados do solo; b) deformação dos agregados nos pontos de contato e c) fluxo plástico do solo com deformação permanente quando o estresse aplicado supera a resistência dos agregados à deformação. Isto acontece mais rapidamente com niveis elevados de umidade no solo (Gupta et al., 1989). O nível de modificações nos atributos físicos do solo depende da textura do solo, do conteúdo de matéria orgânica, da energia de compactação (determinada pela intensidade do pisoteio animal no caso de pastagens) e da umidade do solo no momento em que foi efetuado o pastejo (Dormaar et al., 1989; Proffit et al., 1995; Haveren, 1983), e do tipo de vegetação (Wood \& Blackburn, 1984).

Os efeitos deletérios da pressão exercida pelas patas dos animais têm sido demonstrados em vários atributos físicos do solo. A pesquisa desenvolvida por Carvalho (1976) na área, atualmente estudada, de Terra Roxa Estruturada com pastagem de capim-elefante na ESALQ, a qual foi submetida a dois sistemas de manejo (pastejo rotativo e em faixas), permitiu verificar que 0 pisoteio dos animais, durante quatro anos, aumentou a densidade do solo e 
causou a diminuição do volume total de poros e da macroporosidade numa camada de $7,5 \mathrm{~cm}$ de espessura. $O$ incremento na densidade do solo também foi determinada por Tanner \& Mamaril (1959) e Haveren (1983), mas os resultados variaram com a textura do solo e a lotação animal aplicada. Resultados contrários foram determinados por Gijsman \& Thomas (1996) e Profitt et al. (1993), visto que esses autores não encontraram variações nos valores de densidade do solo.

Em solos de textura argilosa, o aumento na densidade ocasionou uma redução na condutividade hidráulica saturada, principalmente quando o pastejo foi realizado com elevada umidade no solo, e esses efeitos foram maiores quanto maior a carga animal (Mead \& Chan, 1992; Stephenson \& Veigel, 1987; Willatt \& Pullar, 1983). A redução no volume do solo diminuiu o volume de macroporos e a taxa de infiltração, alterando a capacidade de armazenamento de água do solo (Proffitt et al., 1993; Proffitt et al., 1995; Warren et al., 1986a). Outros efeitos têm sido evidenciados, tais como modificações na estabilidade e no tamanho dos agregados (Warren et al., 1986b), e aumento na resistência à penetração das raízes no solo (Mead \& Chan, 1992; Murphy et al, 1995; Willatt \& Pullar, 1983).

Unger \& Kaspar (1994) indicaram que solos com culturas anuais apresentaram aumento da densidade e da resistência à penetração nas linhas trafegadas por maquinaria agrícola quando comparadas à não trafegadas. No entanto, as características físicas do solo diretamente sob as plantas e entre elas têm sido pouco avaliadas. Hook et al. (1991) provaram que havia uma tendência de redução na densidade do solo abaixo de plantas de Bouteloua gracilis (gramínea perene) em comparação com a área situada entre plantas.

O efeito da posição relativa às plantas e da área entre plantas nas propriedades físicas do solo foi estudado em solos com culturas anuais. Silva et al. (1997b) e Correchel (1998) demonstraram a ocorrência de menores valores da densidade do solo nas linhas das plantas da cultura de milho do que nas 
entrelinhas. Os maiores valores nas entrelinhas da cultura são reflexos do tráfego de máquinas e equipamentos e do menor volume de raízes ali presentes.

A variabilidade espacial nas propriedades físicas do solo reflete distintas condições, no espaço, de outras propriedades relacionadas com o crescimento das plantas. Implica em locais com diferentes condições de aeração, disponibilidade de água e resistência mecânica que deverão ser integrados pelas raizes das culturas durante o seu crescimento. Além disso, interações com nutrientes, em termos de quantidade e/ou formas disponiveis, bem como em relação a eficiência de absorção ocorrem em função dos níveis de aeração e atividade biológicas diferenciados nessas posições.

Douglas (1994) assinalou que os efeitos negativos da compactação do solo nos niveis de produção das forrageiras podem ser algumas vezes superados mediante a adição de doses elevadas de fertilizantes. No entanto, em geral, as respostas obtidas foram reduzidas. Nessas circunstâncias as quantidades de adubo não utilizadas pelas pastagens foram perdidas por lixiviação ou volatilização. Soane \& Van Ouwerkerk (1995) também indicaram que a presença de camadas compactadas reduziram a eficiência de utilização dos fertilizantes nitrogenados pelas pastagens.

As raízes das plantas que crescem sob condições de estresse, como as geradas pela alta resistência mecânica do solo ou a falta de umidade no solo, parecem ser capazes de identificar essas condições e de emitir um tipo de sinal para a parte aérea. A resposta das plantas a esse sinal é a diminuição da taxa de expansão das folhas e, às vezes, diminuição da taxa de aparecimento de folhas. Essa resposta foi verificada em culturas anuais que cresceram com parte ou com todo seu sistema radicular em condições restritivas (Blackman \& Davies, 1985; Blum et al.,1991; Masle \& Passioura, 1987; Passioura, 1988a; Passioura, 1991b; Saab \& Sharp, 1989). Em todos os casos a produção de biomassa aérea, principalmente a produção de folhas, foi 
mais afetada que o crescimento das raízes. Este tipo de resposta, se comprovada em pastagens, pode comprometer severamente a sua produtividade.

Davies et al. (1989) demostraram que a produtividade de pastagens de 26 anos de trevo branco e azevem foi significativamente incrementada com a ruptura da camada compactada do solo a uma profundidade de $15 \mathrm{~cm}$, mantendo-se o nível de adubação. Esse aumento foi decorrente da diminuição da densidade do solo, e do aumento da porosidade do solo, da quantidade de água disponivel para as plantas, e da quantidade de nutrientes absorvidos ( $N$, P, e K, principalmente). Harrison et al. (1994) estudaram o efeito da subsolagem a duas profundidades $(27$ e $47 \mathrm{~cm}$ ) numa pastagens de 8 anos de Lolium perenne. Verificaram que houve diminuição da densidade do solo e aumento da condutividade hidraúlica, o qual permitiu um maior desenvolvimento do sistema radicular, principalmente nas camadas inferiores a $30 \mathrm{~cm}$. $O$ resultado foi o incremento na produção de forragem.

Os solos podem apresentar uma ampla variação espacial nos atributos físicos e químicos. Naqueles em que temporalmente as plantas ocupam a mesma posição, a distribuição específica do sistema radicular associado aos efeitos do manejo podem incrementar essa variabilidade devido ao acúmulo de matéria orgânica e nutrientes $e$, pelas modificaçōes nas propriedades físicas do solo (Hook et al., 1991).

A avaliação dessas condições é importante em termos ambientais e econômicos, uma vez que através de sistemas mais precisos de amostragens de solo pode-se aumentar a eficiência de utilização dos fertilizantes, contribuindo para a obtenção das máximas produtividades. A utilização de técnicas de medição específicas e escalas adequadas são requeridas para identificar as propriedades e/ou heterogeneidade do meio no qual as plantas crescem (Dexter, 1997). O sistema estudado, pastagem de capim-elefante submetido a pastejo rotacionado intensivo, apresenta microlocais com e sem 
plantas. No entanto, são escassas as informações a respeito do contraste das propriedades químicas e físicas entre esses microsítios. 


\section{MATERIAL E MÉTODOS}

\subsection{Caracterização da área e do solo}

A pesquisa foi desenvolvida na área experimental do Departamento de Zootecnia da Escola Superior de Agricultura "Luiz de Queiroz", no Município de Piracicaba, Estado de São Paulo, localizado entre as coordenadas geográficas $22^{\circ} 42^{\prime}$ de latitude sul e $47^{\circ} 38^{\prime}$ de longitude oeste, e a $538 \mathrm{~m}$ de altitude acima do nível do mar.

O clima, segundo a classificação de Köeppen, corresponde a Cwa (mesotérmico úmido subtropical de inverno seco). A precipitação pluviométrica média anual é de $1253 \mathrm{~mm}$. A temperatura média anual é de $21,1^{\circ} \mathrm{C}$, com média do mês mais frio de $10^{\circ} \mathrm{C}$ e do mês mais quente de $30^{\circ} \mathrm{C}$ (Ometto, 1989).

O solo na área experimental foi classificado como Terra Roxa Estruturada Eutrófico ( $\mathrm{TRE}_{\mathrm{e}}$ ), com horizonte $\mathrm{A}$ moderado, textura argilosa/muito argilosa (Kandiufalfic Eutrudox) (Vidal Torrado \& Sparovek, 1993)', apresentando $27,2 \%$ de areia, $54,6 \%$ de argila e $18,2 \%$ de silte.

A área possui sistema de exploração da pastagens intensivo, com rotação dos animais em piquetes de $1000 \mathrm{~m}^{2}(20 \mathrm{~m} \times 50 \mathrm{~m})$. A pastagem foi estabelecida em 1963/64, utilizando o capim-elefante (Pennisetum purpureum Schum) como espécie forrageira.

\footnotetext{
'VIDAL TORRADO, P.; SPAROVEK, G. (Departamento de Solos, ESALQ, USP, Piracicaba). Mapa pedológico detalhado 1:10000 do Campus "Luiz de Queiroz", Universidade de São Paulo, Piracicaba (SP), 1993.
} 
O sistema de pastejo rotacionado intensivo vem sendo utilizado desde 1971. Até 1993, os piquetes foram pastejados com vacas leiteiras e, a partir desse ano, com vacas secas e gado de corte da raça Nelore, variando o peso dos animais de 450 a $600 \mathrm{~kg}$. A taxa de lotação empregada tem sido incrementada com os anos conforme o aumento de produtividade do capimelefante, sendo atualmente de 11-12 unidades animais por ha (UA/ha) durante o verão e 2,5-3 UA/ha durante o inverno. O ciclo de pastejo (periodo compreendido entre o início de um período de pastejo e o início do próximo período de pastejo no mesmo piquete) é de 45 dias, sendo que os animais permanecem nos piquetes durante um dia.

Com o estabelecimento da pastagem foi implementado um programa de elevação da fertilidade do solo. Tal programa baseia-se no aumento dos teores de nutrientes no solo através de adubações, as quais são realizadas levando-se em consideração as quantidades de nutrientes extraídos pelas plantas e exportados da área. A aplicação de fertilizantes é efetuada manualmente em cobertura durante os meses de outubro a abril, época de crescimento ativo das plantas, após a cada pastejo. Os adubos utilizados são: uréia, super simples e cloreto de potássio.

A forrageira é adubada anualmente com nitrogênio (300 kg N ha-1 a $600 \mathrm{~kg} \mathrm{~N} \mathrm{ha}^{-1}$ ), fósforo (100 kg $\left.\mathrm{P}_{2} \mathrm{O}_{5} \mathrm{ha}^{-1}\right)$ e potássio $\left(300 \mathrm{~kg} \mathrm{~K}_{2} \mathrm{O} \mathrm{ha}{ }^{-1}\right)$, sendo que essas quantidades podem variar em função da necessidade de forragem $e$ dos resultados das análise de solo, os quais são realizados uma vez por ano. A aplicação de calcário é realizada para manter a saturação por bases no valor de $80 \%$ (Corsi, $1998^{2}$ ).

\footnotetext{
${ }^{2}$ CORSI, M. (Departamento de Zootecnia, ESALQ, USP, Piracicaba). Comunicação pessoal,
} 1998. 


\subsection{Amostragem}

Para a realização do estudo foi escolhido um piquete, com superfície de $1000 \mathrm{~m}^{2}(20 \mathrm{~m} \times 50 \mathrm{~m})$, situado na posição topográfica da meia encosta. $\mathrm{Na}$ área foram localizados pontos de amostragem em duas posições espaciais:

a) no solo debaixo das touceiras (DT) de capim-elefante, para o qual a biomassa da parte aérea das plantas foi retirada, utilizando um enxadão, sem alterar a condição do solo no local. Em cada ponto de amostragem foi retirada uma touceira.

b) no solo descoberto entre duas touceiras (ET) de capim-elefante, e imediatamente ao lado de cada ponto da posição DT.

No local foram localizados um total de 48 pontos de amostragem, sendo que 24 pontos corresponderam à posição DT, e os outros 24 à posição ET. A área foi dividida numa malha com espaçamento regular de $4 \mathrm{~m}$ por $8 \mathrm{~m}$ entre os pontos, o que resultou num retângulo de 4 colunas e 6 linhas. $O$ esquema de amostragem é ilustrado nas Figuras 1 e 2 . Em cada ponto foram coletadas amostras com estrutura deformada $e$ indeformada, na camada superficial $0-10 \mathrm{~cm}$.

\subsection{Determinações}

A amostras deformadas foram secadas ao ar durante 72 horas e separadas em duas subamostras. Uma subamostra foi passada em peneira com abertura de malha de $2 \mathrm{~mm}$ e foram efetuadas as análises químicas de rotina conforme a metodologia descrita por Raij et al. (1987). Os parâmetros avaliados foram pH (em $\mathrm{CaCl}_{2} 0,01 \mathrm{M}$ ), carbono orgânico (através de oxidação com solução de dicromato de potássio), fósforo disponível, potássio, cálcio e magnésio trocáveis (extraídos com resina trocadora de ions), enxofre como sulfato (pelo método turbidimétrico), CTC, SB e \%V. 
A outra subamostra foi utilizada para determinar a distribuição do tamanho dos agregados e o diâmetro médio ponderado. Para a separação dos agregados foi utilizado um sistema de separação dos agregados secos por vibração, com um tempo de agitação de um minuto por amostra, e peneiras com os seguintes diâmetros: $12,5 \mathrm{~mm}, 8 \mathrm{~mm}, 4 \mathrm{~mm}, 2 \mathrm{~mm}, 1 \mathrm{~mm}, 0,5 \mathrm{~mm}$, $0,250 \mathrm{~mm}$ e $0,100 \mathrm{~mm}$. O material retido em cada peneira, após pesagem, teve sua massa corrigida para massa seca em estufa a $105^{\circ} \mathrm{C}$.

A partir dos resultados foi calculado o diâmetro médio ponderado (DMG) dos agregados de acordo com a metodologia descrita por White (1993), utilizando a equação (1).

$$
D M G=\sum_{i=1}^{n} \quad X_{i} * W_{i}
$$

$\mathrm{Na}$ equação (1) $X_{i}$ é o diâmetro médio da fração $i$, que corresponde ao ponto médio entre o tamanho da peneira na qual o material foi retido e o tamanho da peneira de diâmetro imediatamente superior, e $W_{i}$ é a proporção do total da amostra retida na peneira

A distribuição do tamanho dos agregados foi caraterizada através da função de Rosin-Rammler, empregada por Perfect et al. (1993):

$$
P(X>x)=100 \exp \left[-(x / \alpha)^{\beta}\right]
$$

$\mathrm{Na}$ equação (2), $P(X>x)$ é a porcentagem de agregados (do peso total) com tamanho maior que a peneira de tamanho $x$, exp é a função exponencial, e $\alpha$ e $\beta$ são constantes relacionadas a carateristicas de forma e tamanho da distribuição. A constante $\alpha$ representa o tamanho dos agregados que correspondem ao 36,78 percentil da distribuição de freqüência acumulada, sendo semelhante ao 50 percentil da distribuição normal. A constante $\beta$ é análoga ao desvio padrão da distribuição normal. O modelo da equação (2) foi ajustado usando o método de regressão não linear multivariada (Statistical Analysis System Institute, 1991). 
Nas amostras indeformadas, coletadas a partir de anéis volumétricos de $7 \mathrm{~cm}$ altura por $7 \mathrm{~cm}$ diâmetro, foram realizadas medidas de resistência do solo à penetração. As amostras foram saturadas com água por 24 horas e em seguida submetidas a diferentes potenciais em mesa de tensão e em panelas de pressão de Richards conforme Klute (1986), sendo utilizadas seis amostras por potencial. Foram aplicados os potenciais de $-10,-30,-50,-100,-300,-700$, -1000 e $-15000 \mathrm{~cm}$, com o objetivo de simular um gradiente de umidade entre as amostras. Após atingir o equilibrio, a resistência à penetração foi medida em cada amostra empregando um penetrômetro com velocidade constante de penetração de $1 \mathrm{~cm} \min ^{-1}$ e um cone com diâmetro de base de $4 \mathrm{~mm}$. As medidas de resistência do solo foram coletadas por meio de um sistema automatizado de aquisição de dados. Após a determinação da resistência à penetração, as amostras foram secas em estufa a $105^{\circ} \mathrm{C}$ por 24 horas e determinada a densidade do solo (Ds) de acordo com Blake \& Hartge (1986).

Os dados de resistência à penetração foram ajustados utilizando o modelo proposto por Busscher (1990):

$$
R P=d \theta^{e} D_{s}^{f}
$$

ou alternativamente:

$$
\ln R P=\ln d+e \ln \theta+f \ln D_{s}
$$

Na equação (4) o In d é calculado como mostrado na equação (5).

$$
\text { In } d=(d 0+d 1 * \text { posição }), \quad \text { posição: } 0=D T, 1=E T
$$

$\mathrm{Na}$ equação (3) e (4) $\theta$ é o conteúdo de umidade volumétrico $\left(\mathrm{cm}^{3}\right.$ $\left.\mathrm{cm}^{-3}\right), \mathrm{D}_{\mathrm{s}}$ é a densidade do solo $\left(\mathrm{g} \mathrm{cm}^{-3}\right), d, e, f$ são constantes, e RP é a resistência à penetração (MPa). O efeito da posição (DT e ET) foi incorporado como variáveis qualitativas ( $D T=0$ e $E T=1$ ) dentro do coeficiente $d . O$ ajuste do modelo da equação (4) foi realizado utilizando os dados de $\theta$ e $D_{s}$ das duas posições espaciais conjuntamente. Dessa forma, o efeito da posição DT e ET é mostrado num único coeficiente, o coeficiente $d$. 
As análises estatísticas foram realizadas com o "software" estatístico SAS (Statistical Analysis System Institute, 1991), empregando o teste t para amostras independentes para comparar os resultados nas posições DT e ET. O Modelo da equação (4) foi ajustado através do procedimento de regressão multivariada, utilizando o método de Gauss-Newton (Statistical Analysis System Institute, 1991). 


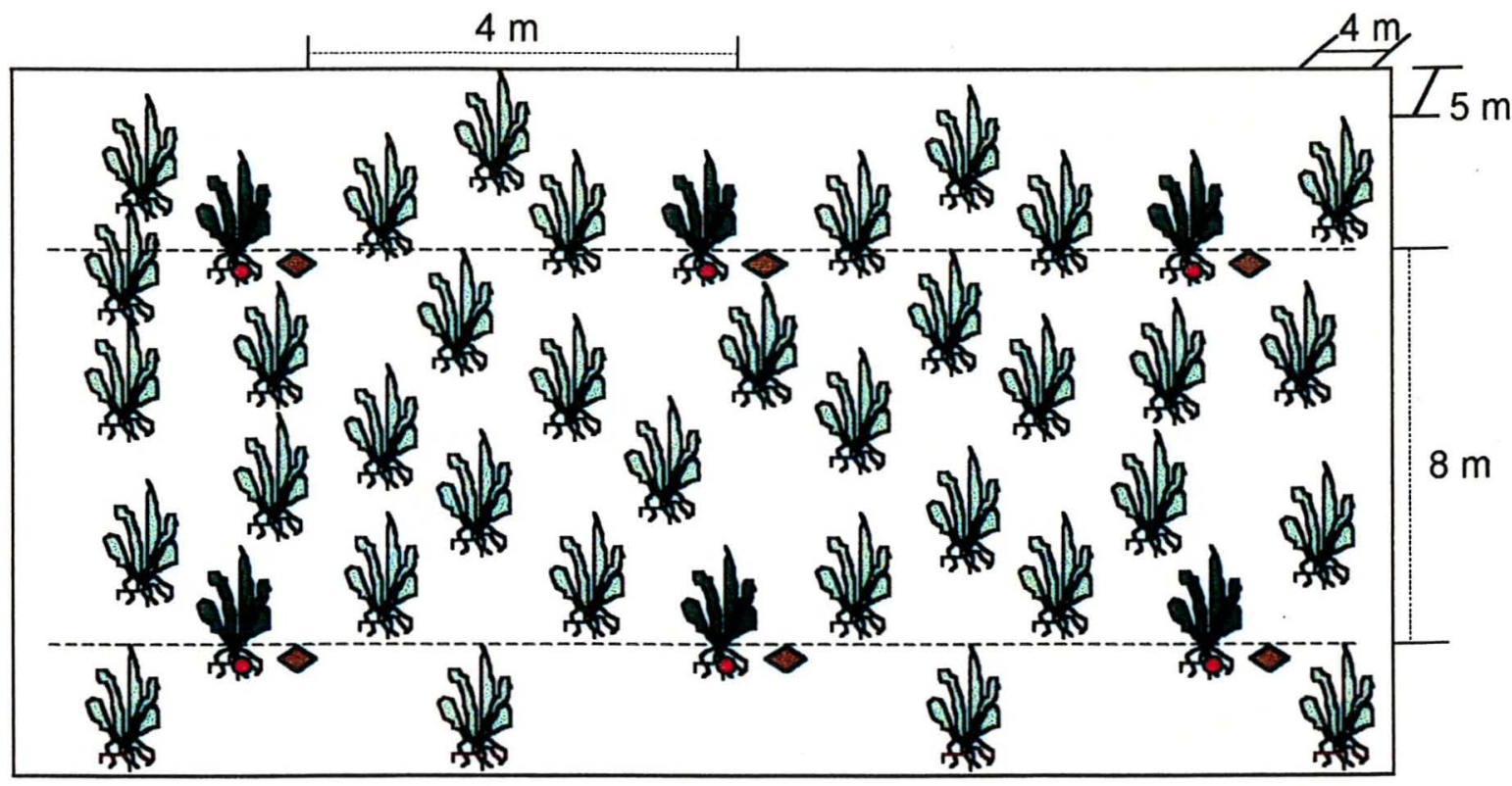

Figura 1 - Esquema de coleta das amostras com estrutura indeformada

e deformada no solo TRE .

- Parcelas de amostragem correspondentes à posição DT

- Parcelas de amostragem correspondentes à posição ET

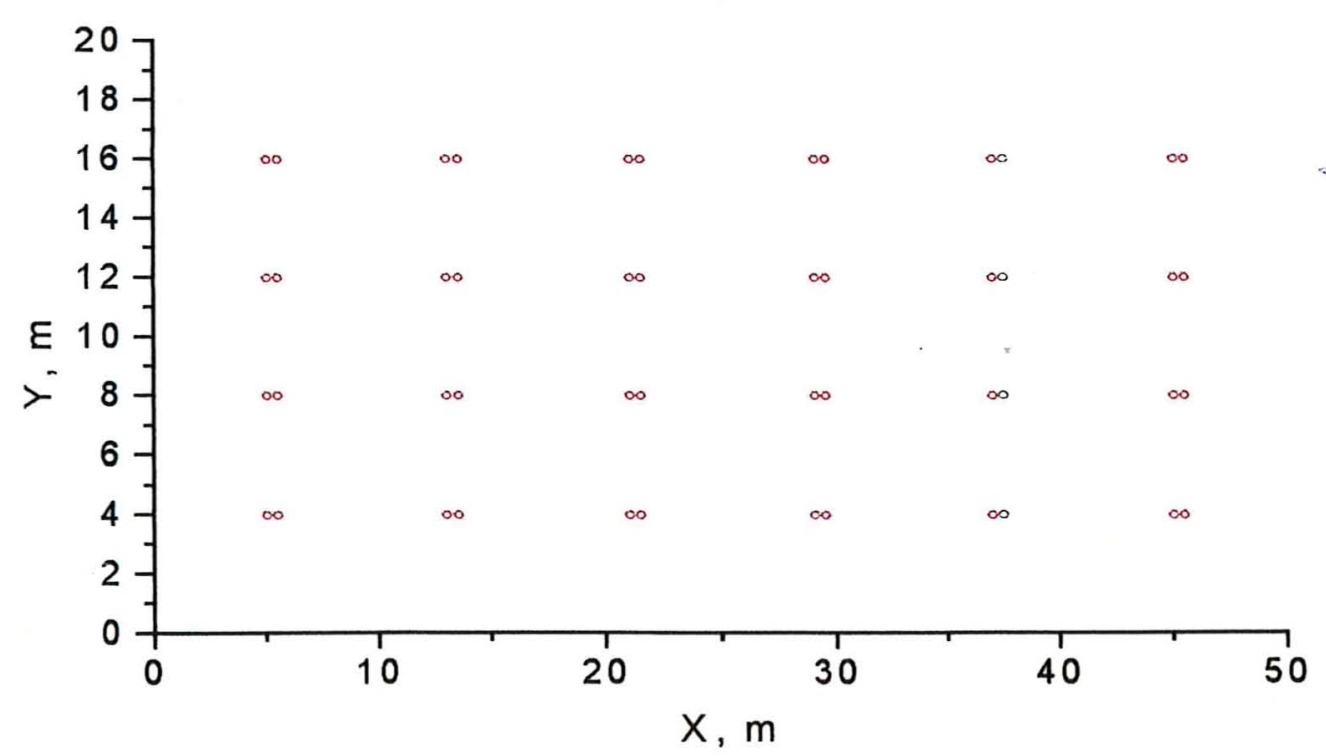

Figura 2 - Coordenadas dos pontos de amostragem. 


\section{RESULTADOS E DISCUSSÃO}

Os momentos estatísticos das variáveis analisadas, nas posições sob as touceiras (DT) e entre as touceiras (ET), são apresentados na Tabela 1. O nivel de significância para o teste de comparação de médias (teste $t$ ) e 0 teste de comparação de variâncias (teste F) são mostrados na Tabela 2.

Tabela 1. Momentos estatísticos dos atributos químicos do solo nas posições DT e ET.

\begin{tabular}{ccccccccc}
\hline Variáveis & $\begin{array}{c}\text { Média } \\
\text { DT }\end{array}$ & $\begin{array}{c}\text { Média } \\
\text { ET }\end{array}$ & CV & CV & MIN. & MIN. & MÁX. & MÁX. \\
& $\mathrm{N}=24$ & $\mathrm{~N}=24$ & & & DT & ET & DT & ET \\
\hline pH & 5,6 & 5,6 & 8,8 & 8,8 & 4,3 & 4,3 & 6,2 & 6,3 \\
MO & 49,70 & 49,70 & 16,1 & 23,1 & 37,0 & 33,0 & 67,0 & 77,0 \\
P & 83,96 & 83,92 & 45,2 & 40,6 & 37,0 & 27,0 & 210,0 & 189,0 \\
K & 12,03 & 11,05 & 51,5 & 53,1 & 4,0 & 4,0 & 34,1 & 33,8 \\
$\mathrm{Ca}$ & 80,21 & 81,96 & 43,8 & 31,1 & 38,0 & 38,0 & 146,0 & 140,0 \\
$\mathrm{Mg}$ & 41,83 & 40,46 & 64,6 & 43,6 & 15,0 & 14,0 & 120,0 & 90,0 \\
$\mathrm{~S}$ & 37,50 & 34,83 & 39,9 & 42,1 & 17,8 & 17,8 & 77,8 & 74,2 \\
$\mathrm{H}^{+}+\mathrm{Al}{ }^{+3}$ & 33,58 & 34,42 & 60,7 & 63,9 & 16,0 & 13,0 & 109,0 & 98,0 \\
$\mathrm{CTC}$ & 167,65 & 167,88 & 32,3 & 19,2 & 124,9 & 123,0 & 295,7 & 259,6 \\
$\mathrm{SB}$ & 134,07 & 133,46 & 46,1 & 34,1 & 63,3 & 65,1 & 279,7 & 241,6 \\
$\mathrm{~V}$ & 78,86 & 78,08 & 16,5 & 19,4 & 37,0 & 41,0 & 95,0 & 95,0 \\
\hline
\end{tabular}

${ }^{*} \mathrm{pH}\left(\mathrm{CaCl}_{2}\right) ; \mathrm{MO}\left(\mathrm{g} \mathrm{kg}^{-1}\right) ; \mathrm{P}, \mathrm{S}-\mathrm{SO}_{4}\left(\mathrm{mg} \mathrm{dm}^{-3}\right) ; \mathrm{K}, \mathrm{Ca}, \mathrm{Mg}, \mathrm{H}^{+}+\mathrm{Al}^{+3}, \mathrm{CTC}, \mathrm{SB}$ $\left(\mathrm{mmol}_{\mathrm{c}} \mathrm{dm}^{-3}\right) ; \mathrm{V}(\%), \mathrm{CV}(\%)$. 
Tabela 2. Niveis de significância associados aos testes de comparação de médias (teste $t$ ) e de variâncias (teste $F$ ), para as variáveis analisadas.

\begin{tabular}{ccccc}
\hline Variáveis & $\mathrm{t}$ & Prob $>|\mathrm{t}|$ & $\mathrm{F}$ & Prob $>\mathrm{F}$ \\
\hline $\mathrm{pH}$ & 0,0307 & 0,9757 & 1,22 & 0,6327 \\
$\mathrm{MO}$ & 0,0000 & 1,0000 & 2,16 & 0,0706 \\
$\mathrm{P}$ & 0,0034 & 0,9973 & 1,11 & 0,7992 \\
$\mathrm{~K}$ & 0,5615 & 0,5772 & 1,12 & 0,7864 \\
$\mathrm{Ca}$ & $-0,2443$ & 0,8081 & 1,12 & 0,7912 \\
$\mathrm{Mg}$ & 0,2540 & 0,8006 & 1,25 & 0,5908 \\
$\mathrm{~S}$ & 0,6257 & 0,5346 & 1,04 & 0,9210 \\
$\mathrm{H}^{+}+\mathrm{Al}{ }^{+3}$ & $-0,1359$ & 0,8925 & 1,16 & 0,7254 \\
$\mathrm{CTC}$ & $-0,0242$ & 0,9808 & 1,08 & 0,9603 \\
$\mathrm{SB}$ & 0,0470 & 0,9627 & 1,10 & 0,8270 \\
$\mathrm{~V}$ & 0,1944 & 0,8467 & 1,36 & 0,4675 \\
\hline
\end{tabular}

${ }^{*} \mathrm{pH}\left(\mathrm{CaCl}_{2}\right) ; \mathrm{MO}\left(\mathrm{g} \mathrm{kg}^{-1}\right) ; \mathrm{P}, \mathrm{S}-\mathrm{SO}_{4}\left(\mathrm{mg} \mathrm{dm}^{-3}\right) ; \mathrm{K}, \mathrm{Ca}, \mathrm{Mg}, \mathrm{H}^{+}+\mathrm{Al}^{+3}, \mathrm{CTC}$, $\mathrm{SB}\left(\mathrm{mmol}_{\mathrm{c}} \mathrm{dm}^{-3}\right) ; \mathrm{V}(\%), \mathrm{CV}(\%)$.

A análise estatística dos dados indicou não haver diferenças significativas entre os valores dos atributos quimicos nas posições amostradas. $O$ teste $F$ demonstrou que as variâncias de todas as variáveis químicas estudados foram iguais. O menor coeficiente de variação $(8,8 \%)$ correspondeu à variável pH, concordando com o observado por Prevedello (1987). Entretanto, os valores do coeficiente de variação das outras propriedades químicas foram mais elevados, nas duas posições espaciais estudadas. Prevedello (1987) analisou a variabilidade espacial de parâmetros físicos e químicos para o mesmo solo sob culturas anuais, numa área próxima à deste estudo. As diferenças nos valores dos coeficientes de variação podem ser resultado dos diferentes sistemas de cultivo $e$ da distribuição de adubos $e$ dejeções na pastagem. 
Os valores médios determinados, para as duas posiçōes espaciais, podem ser classificados como muito altos, no caso do $P$ e $K$, e como altos no caso de $\mathrm{Ca}, \mathrm{Mg}$ e $\mathrm{S}$. Os valores de matéria orgânica e CTC também são elevados. A acidez do solo é considerada baixa e a saturação por bases (V\%) elevada, superando os valores recomendados para a formação e/ou manutenção das gramíneas do grupo I, dentro do qual se encontra o capimelefante (Raij et al., 1996).

Comparando os resultados das análises de solo deste estudo, na posição ET, com os encontrados por Carvalho (1976), na mesma área, se observa que houve um incremento de $25 \%$ no teor de $\mathrm{MO}$, de $26 \%, 60 \%$, e $64 \%$ nos conteúdos de $\mathrm{Ca}, \mathrm{Mg}$ e $\mathrm{K}$ respectivamente e, de $14 \%$ no valor do $\mathrm{pH}$ do solo. O valor da CTC aumentou num $10 \%$, o qual pode estar associado ao incremento no teor de MO do solo e ao efeito do calcário.

No sistema estudado não foram identificadas "ilhas de fertilidade" química, conforme sugeriram Hook et al. (1991), Kelly et al. (1996) e Vinton \& Burke (1995). Esses autores assinalaram que plantas individuais concentraram biomassa, carbono e nitrogênio orgânico debaixo delas, induzindo a formação de "ilhas de fertilidade" química. Os fatores que determinaram a ocorrência do processo de concentração desses nutrientes em forrageiras cespitosas foram: a) elevada proporção de raízes que forneceram exudados e matéria orgânica ao solo após a sua decomposição e b) acúmulo de material orgânico na base e ao redor das plantas.

Hook et al. (1991) mencionaram que, se a distribuição espacial dos residuos orgânicos efetivamente regula a distribuiçäo do carbono e do nitrogênio no solo, é possível que uma distribuição horizontal mais uniforme desses nutrientes ocorra com o incremento da taxa de lotação animal.

A ausência de "ilhas de fertilidade quimica" neste estudo pode ser associada a vários fatores. Um dos fatores pode estar relacionado à separação entre as plantas, a qual é afetada pela taxa de lotação animal. Com alta lotação 
animal a densidade de plantas é maior que a densidade encontrada sob pastejo extensivo ou contínuo. Em sistemas de pastejo intensivos ocorre uma relação inversa entre densidade de plantas e o diâmetro basal das mesmas, alterando a habilidade das plantas em acumular nutrientes na rizosfera (Derner et al., 1997; Hook et al., 1991). O capim-elefante é uma espécie cespitosa que, no sistema estudado, forma touceiras separadas por uma distância que varia entre 0,6 m 0,8 m. Isso implica numa elevada densidade de plantas e na ausência de espaços grandes de solo descoberto. As plantas possuem um sistema radicular muito ramificado, constituído principalmente de raízes finas. Parte desse sistema se renova anualmente fornecendo ao solo elevadas quantidades de carbono e nutrientes após a sua decomposição. Dessa forma, a elevada densidade de plantas pode estar associada à uniformização espacial dos atributos químicos do solo, como indicado por Derner et al. (1997) e Hook et al. (1991).

Outro fator associado à ausência de "ilhas de fertilidade" de carbono e nitrogênio é a quantidade e qualidade do material orgânico depositado entre as plantas, através dos resíduos vegetais e animais.

O volume de residuos vegetais depende da produtividade da pastagem. No sistema estudado, a produção foi de $23,59 \mathrm{Mg} \mathrm{MS} \mathrm{ha}^{-1}$ para o periodo outubro-abril, com $22 \%$ de perdas na forma de resíduos vegetais na superfície do solo (Balsalobre, 1996). Valores de perdas que variaram de 15 a $26 \%$ do total da forragem disponivel, também foram assinalados por Hillesheim (1987) para a mesma pastagem. A quantidade elevada de resíduos vegetais (5,2 $\left.\mathrm{MgMS} \mathrm{ha}^{-1}\right)$, depositadas na posição $\mathrm{ET}$, pode estar contribuindo para elevar o teor de matéria orgânica do solo entre as plantas, principalmente da fração temporária, como assinalado por Tisdall \& Oades (1982).

O volume de excreções animais é determinado, principalmente, pelo tipo e tamanho dos animais e pela taxa de lotação utilizada. No sistema estudado, devido à alta lotação animal utilizada no pastejo e ao tamanho dos 
animais (peso maior que $450 \mathrm{~kg}$ ), o aporte de matéria orgânica via excreções pode estar contribuindo para elevar o teor de matéria orgânica do solo, principalmente da fração transitória (Tisdall \& Oades, 1982) de forma semelhante em toda a área, desde que sistemas de pastejo intensivos produzem uma distribuição mais uniforme das fezes e urina dos animais (Haynes \& Williams, 1993; Murphy et al., 1995) e dos nutrientes no solo.

A heterogeneidade espacial dos nutrientes no solo é determinada pelos mecanismos de transporte de íons no solo e de absorção pelas raizes (Marschner, 1995). Na interface raiz-solo pode ocorrer acúmulo dos nutrientes que se movimentam no solo preferencialmente por fluxo de massa $(\mathrm{N}, \mathrm{Ca}, \mathrm{Mg}$, S) e o esgotamento daqueles que se movimentam por difusão ( $P$ e K) (Barber, 1984, Marschner, 1995; Robinson, 1994).

No sistema estudado, o fato de não existir acúmulo de $\mathrm{N}, \mathrm{Ca}, \mathrm{Mg}$ e $\mathrm{S}$, na posição DT, pode estar associado ao sistema de pastejo intensivo utilizado. Neste sistema a altura de pastejo chega até os $0,40 \mathrm{~m}$ reduzindo a área foliar remanescente ao mínimo necessário para uma rebrota vigorosa da forrageira. A desfoliação intensa e periódica determina que os nutrientes absorvidos sejam, preferencialmente, transportados da raiz para os novos pontos de crescimento na parte aérea. Além disso, produções elevadas (como as atingidas no sistema estudado) exigem que grandes quantidades de nutrientes sejam absorvidas, o qual pode estar dificultando o processo de acúmulo de nutrientes na rizosfera. Manley et al. (1995) assinalaram que, como conseqüência de elevadas taxas de absorção de nutrientes, às vezes pode ocorrer uma diminuição da concentração de nutrientes nessa região.

Por outro lado, no sistema estudado periodicamente é efetuada a aplicação de adubos e calcário. Esta prática pode estar incrementando o conteúdo de $\mathrm{Ca}, \mathrm{Mg}$, Se $\mathrm{N}$ no solo, e contribuindo à uniformização espacial dos nutrientes, uma vez que esses íons são rapidamente movimentados da posição ET para a rizosfera. 
Em função da maior absorção de cátions na rizosfera é de se esperar um valor de $\mathrm{pH}$ mais elevado entre as plantas que sob as plantas, como mencionado por Goss (1987) e Robinson (1994). Isto não foi constatado neste estudo. As raízes liberam íons hidrogênio, íons bicarbonatos e ácidos orgânicos na rizosfera para equilibrar as cargas elétricas geradas no processo de absorção de cátions. Isso leva à diminuição do pH na posição DT, tal como mencionado por vários autores (Glinski \& Lipiec, 1990; Marschner, 1995; Rendig \& Taylor, 1989). Entretanto, a separação existente entre as plantas $(0,60 \mathrm{~m}-0,80 \mathrm{~m})$ permite que uma certa quantidade dos fertilizantes nitrogenados, fosfatados e potássicos seja aplicada diretamente na posição ET. Esses adubos reagem no solo de formas variadas, alterando o $\mathrm{pH}$ do solo. No caso da uréia, a sua decomposição leva à liberação de prótons ocasionando a diminuição do $\mathrm{pH}$ do solo. Os processos mencionados ocorrem simultaneamente nas posições ET e DT, e podem estar associados à uniformização dos valores de $\mathrm{pH}$ do solo.

Em relação aos nutrientes $\mathrm{P}$ e K os resultados também discordaram aos observados por Marschner (1995) e Robinson (1994). Uma possivel explicação para a ausência de diferenças significativas nos teores desses nutrientes, nas posições DT e ET, está nas condições físicas do solo nas posições DT e ET.

Um dos atributos físicos que pode estar associado à ausência de "ilhas de fertilidade" de P e K é o tamanho dos agregados do solo. O P e K se movimentam no solo, preferencialmente, através do processo de difusão, e este processo é favorecido quando o tamanho dos agregados é pequeno e uniforme (Braunack \& Dexter, 1989b; Horn et al., 1994). Solos com estrutura degradada, que apresentam agregados com diâmetro menor que $1 \mathrm{~mm}$ ou maior que 10 mm (Tisdall \& Oades, 1982), o movimento dos íons é retardado devido ao incremento da tortuosidade (Hoffmann \& Jungk, 1995; Horn et al., 1994; Shierlaw \& Alston, 1984). O diâmetro médio geométrico (DMG) dos agregados, 
determinado neste estudo, foi $7 \mathrm{~mm}(t=-0,08 ; p>0,93)$ para as duas posições, com somente $15 \%$ dos agregados com tamanho maior que $10 \mathrm{~mm}$. Esse tamanho está dentro do intervalo considerado adequado para favorecer o processo de difusão de íons no solo (Braunack \& Dexter, 1989a; Braunack \& Dexter, 1989b). A concentração elevada de $\mathrm{P}$ e $\mathrm{K}$ no solo (resultado das adubações periódicas) e o DMG adequado dos agregados podem estar facilitando o transporte desses nutrientes da posição ET para as raízes, contribuindo para a uniformização dos valores desses nutrientes nas posições espaciais estudadas.

Outro aspecto importante da estrutura do solo que pode ser alterado pelo manejo é a distribuição do tamanho dos agregados, a qual é considerada um indicador importante do estado de agregação do solo. A análise estatística dos parâmetros do modelo descrito por Perfect et al. (1993) demonstrou que não existem diferenças significativas para o parâmetro $\alpha$ (diâmetro dos agregados) entre as posições ET e DT. Por outro lado, o parâmetro $\beta$ foi significativamente diferente $(p<0,05)$ entre as duas posições espaciais (Tabela 3).

Tabela 3. Valores médios e nível de significância para os parâmetros físicos do solo utilizados no modelo de distribuição do tamanho dos agregados secos.

\begin{tabular}{cccc}
\hline Variáveis & $\begin{array}{c}\text { Média DT } \\
\mathrm{N}=24\end{array}$ & $\begin{array}{c}\text { Média ET } \\
\mathrm{N}=24\end{array}$ & Prob> $|\mathrm{T}|$ \\
\hline$\alpha$ & 10,21 & 11,02 & 0,4822 \\
$\beta$ & 1,12 & 1,05 & 0,0280 \\
\hline
\end{tabular}

O parâmetro $\beta$ é análogo ao desvio padrão da distribuição normal, e quanto menor o seu valor, maior é o desvio. $O$ valor do parâmetro $\beta$ é menor na posição ET que na posição DT. Isso indica que os agregados na posição ET 
apresentaram os maiores desvios em relação à média, para os tamanhos estudados.

A Figura 3 mostra as curvas de freqüência acumulada, estimadas através da equação (2), do peso dos agregados em função de seus tamanhos, debaixo das touceiras e entre as touceiras. As curvas começam a se diferenciar a partir da fração de $4 \mathrm{~mm}$, indicando que os maiores desvios, no peso dos agregados, ocorreram nos tamanhos maiores (12,5 $\mathrm{mm}$ e $8 \mathrm{~mm}$ respectivamente), e na posição ET.

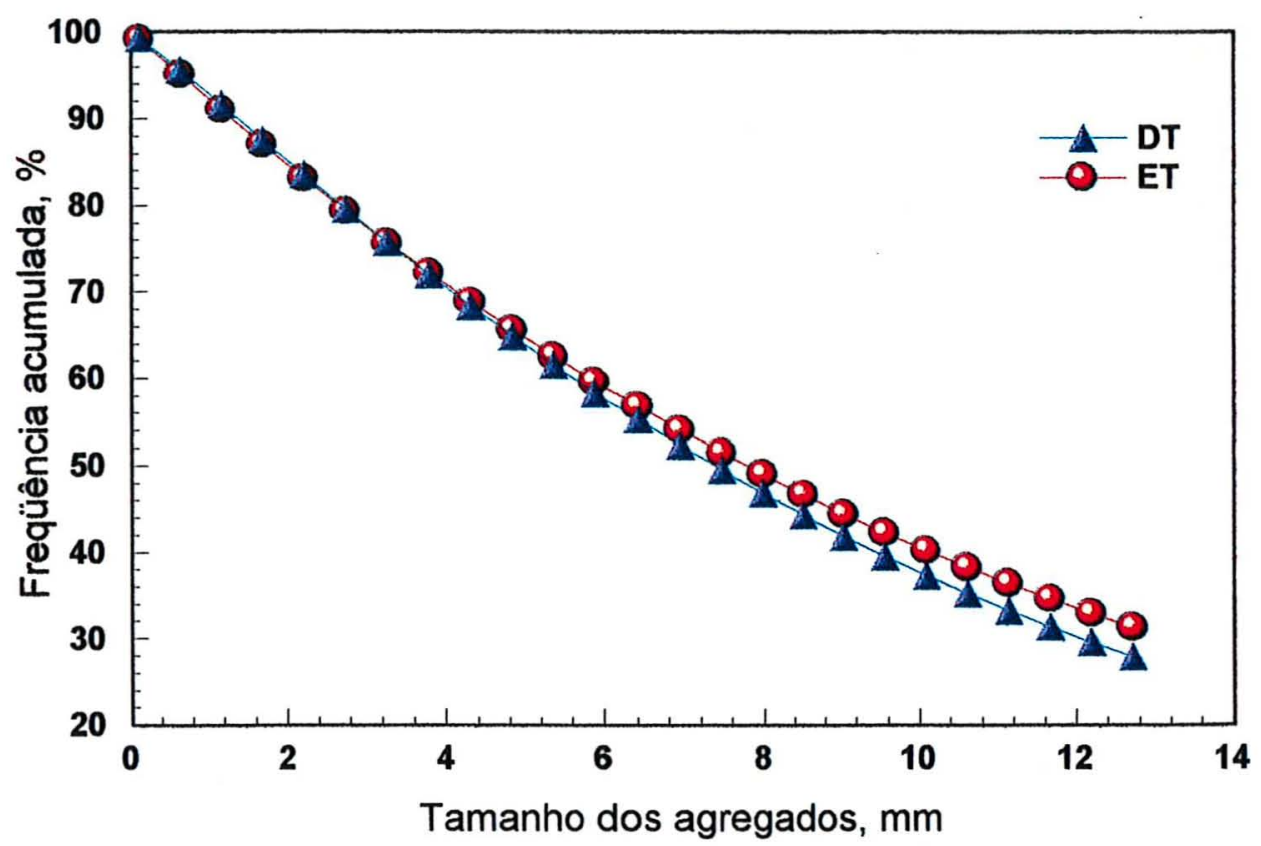

Figura 3 - Freqüência acumulada do peso dos agregados em função do seu tamanho para as posições espaciais debaixo das touceiras e entre as touceiras.

A maior variação no peso dos agregados maiores que $12,5 \mathrm{~mm}$, verificada na posição $E T$, indica que a proporção de agregados grandes, nessa posição, é muito variável no espaço. Duas razões podem estar associadas a esses resultados. A primeira é que os agregados mais afetados pelo pisoteio dos animais são precisamente os de maior tamanho, os quais são considerados menos estáveis (Braunack \& Dexter, 1989a). Quando o pisoteio é realizado com 
- solo seco ocorre desintegração mecânica dos agregados, fazendo com que o tamanho dos agregados diminua. Por outro lado, quando o pisoteio é efetuado com o solo úmido, o processo de compactação conduz à formação de agregados de tamanho maior (Warren et al., 1986b).

A segunda razão está associada ao tipo de matéria orgânica que atua como agente de união das partículas do solo, na formação dos agregados. $\mathrm{Na}$ posição ET, uma fração importante da matéria orgânica do solo é fornecida através das fezes e resíduos vegetais. Esses tipos de matéria orgânica denominadas transitória e temporária, respectivamente, (Tisdall \& Oades, 1982), exercem uma grande influência na formação dos agregados maiores e podem ter favorecido o incremento do tamanho dos agregados, principalmente daqueles maiores que $4 \mathrm{~mm}$. O efeito das fezes no aumento do tamanho dos agregados foi demonstrado por Darwish et al. (1989).

Nas frações de tamanho menor que $4 \mathrm{~mm}$ não houveram diferenças no peso dos agregados entre as posição DT e ET. Isto pode ser decorrente dos elevados conteúdos de matéria orgânica, nas duas posições espaciais, e da influência especifica da matéria orgânica persistente (Tisdall \& Oades, 1982), a qual atua diretamente na formação e estabilidade dos agregados menores.

A reduzida variação nos pesos dos agregados, dentro de cada tamanho estudado, na posição DT, pode ser explicada levando-se em consideração o efeito de estruturação do solo exercido pelas raízes vivas e 0 efeito da matéria orgânica de tipo temporário, a qual é produzida quando as raízes morrem. Esses efeitos já foram mencionados por Glinski \& Lipiec (1990), Horn et al. (1994) e Tisdall \& Oades (1982). Horn et al. (1995) assinalaram que solos com estrutura não degradada são caracterizados por apresentarem agregados de tamanhos heterogêneos, situação observada na posição DT.

A densidade do solo (Ds) é um atributo do solo utilizado, freqüentemente, como indicador do estado de agregação do solo (Gupta et al., 1989). A análise estatistica demonstrou que existem diferenças significativas na 
Ds $(t=-4,19, p<0,001)$ entre as posições amostradas. A Ds foi significativamente menor na posição DT. Os valores médios foram: posição DT, Ds $=1,34 \mathrm{~g} \mathrm{~cm}^{-3} \mathrm{e}$ posição $E T, D s=1,43 \mathrm{~g} \mathrm{~cm}^{3}$.

Os resultados concordam com os determinados por Hook et al. (1991), e discordam dos encontrados por Derner et al. (1997). Demer et al. (1997) não encontraram diferenças significativas nos valores de Ds quando compararam amostras retiradas nas posições que corresponderam ao centro das plantas, à periferia da plantas e entre duas plantas. A falta de concordância dos resultados pode estar associada às diferenças na profundidade de amostragem, uma vez que Derner et al. (1997) extraíram amostras com cilindros de $2 \mathrm{~cm}$ de diâmetro por $30 \mathrm{~cm}$ de comprimento. Hook et al. (1991) atribuíram a menor Ds verificada na posição debaixo das plantas, à maior produção de biomassa, principalmente de raízes, observada nessa posição. $O$ efeito benéfico das raízes na estruturação do solo, na posição debaixo das plantas, também foi assinalado por Derner et al. (1997), Glinski \& Lipiec (1990) e Marshall et al. (1996).

Os valores maiores de Ds observados na posição ET podem estar associados ao processo de compactação do solo produzido pelo pisoteio dos animais. A característica particular do capim-elefante, de formar touceiras, dificulta o pisoteio das plantas. Dessa forma, a área afetada pelo pisoteio é restrita ao espaço entre as plantas. Vários trabalhos demonstram o efeito negativo do pisoteio animal sobre a Ds (Carvalho, 1976; Haveren, 1983; Mead \& Chan, 1992; Murphy et al., 1995; Proffitt et al., 1995; Stephenson \& Veigel, 1987; Tanner \& Mamaril, 1959; Willatt \& Pullar, 1983). O incremento na densidade do solo assinalado por esses autores variou de $7 \%$ até $18 \%$. Essa variação foi determinada, principalmente, pela idade das pastagens, taxa de lotação empregada, umidade no momento do pastejo, tipo de forrageira e textura dos solos. Os resultados de Ds obtidos por Carvalho (1976) na área em estudo, prévio à aplicação do sistema de pastejo rotacionado intensivo (área testemunha), indicam que houve um incremento na Ds de $12 \%$ na posição ET. 
O aumento verificado na densidade do solo, quando comparados os valores de Ds nas posições DT e ET, foi aproximadamente $7 \%$.

Uma das conseqüências do aumento da Ds é a redução na produtividade das forrageiras decorrente do estresse aplicado sobre o sistema radicular, sendo difícil reverter o processo de degradação do solo (Stephenson \& Veigel, 1987). A compactação do solo implica em alterações nos processos químicos e biológicos, afetando adversamente o fornecimento de nutrientes para as plantas. $O$ incremento na densidade do solo pode ocasionar que alguns locais entre e dentro dos agregados apresentem condições de anaerobiose. Microlocais com quantidades insuficientes de $\mathrm{O}_{2}$ resultam em perdas gasosas de $\mathrm{N}$ devido ao processo de desnitrificação. Esse processo é responsável pela baixa eficiência de aproveitamento do $N$ (Douglas, 1994; Soane \& Van Ouwerkerk, 1995). Soane \& Van Ouwerkerk, (1995) mencionaram que em solos compactados sob pastagens foram observadas perdas de até $100 \mathrm{~kg} \mathrm{~N} \mathrm{ha}^{-1}$. Também Liepiec \& Stepniewski (1995) indicaram que a desnitrificação é um dos processos que mais afetam o balanço de $\mathrm{N}$ em solos compactados. Assim, a maior Ds, na posição ET, pode estar induzindo perdas importantes dos fertilizantes nitrogenados aplicados na área estudada.

Outro aspecto a considerar é o efeito da Ds na disponibilidade dos nutrientes $\mathrm{P}$ e K. A maior Ds, na posição $\mathrm{ET}$, pode favorecer a movimentação desses íons para a posição DT, devido ao incremento no conteúdo de água (umidade volumétrica). Isto implica numa disponibilidade maior e numa taxa de consumo mais elevada pelas raizes, sempre que existam condições adequadas de aeração. Shierlaw \& Alston (1984) comprovaram que, em pastagens de Lolium rigidum, o consumo de $P$ aumentou até valores de $D s$ de $1,45 \mathrm{~g} \mathrm{~cm}^{-3}, 0$ qual foi atribuído à maior mobilidade do íon no solo. A partir desse valor de Ds o consumo de $\mathrm{P}$ diminui devido à falta de oxigênio e ao aumento na tortuosidade do sistema poroso. Hoffman \& Jungk (1995) salientaram que o aumento na Ds foi correlacionado, positivamente, com a disponibilidade de $P$, uma vez que a 
compactação incrementou a umidade volumétrica e o coeficiente de difusão do íon no solo.

A Ds afeta, indiretamente, o crescimento das plantas. Entretanto, exerce efeito direto na resistência mecânica do solo que, por sua vez, afeta diretamente o desenvolvimento das culturas (Letey, 1985). A resistência à penetração (RP) é negativamente relacionada com a umidade do solo e positivamente com a Ds, conforme demonstrado pelos coeficientes do modelo utilizado para o ajuste dos dados de RP, Ds e $\theta$ (Tabela 4).

Tabela 4. Resultados da análise de regressão da curva de resistência à penetração.

\begin{tabular}{cccc}
\hline Coeficientes & Valores & $t$ & Prob $>|t|$ \\
\hline$D_{0}$ & $-3,7496$ & $-20,094$ & 0,0001 \\
$D_{1}$ & 0,1674 & 3,626 & 0,0007 \\
$e$ & $-3,8539$ & $-23,496$ & 0,0001 \\
$f$ & 1,6906 & 4,746 & 0,0001 \\
\hline
\end{tabular}

$F=205,973, p<0,0001, R^{2}=0,93$.

O modelo da curva de RP expresso em função das propriedades do solo (Ds e $\theta$ ), para as posições DT e ET, é mostrado nas equações (6) e (7).

Modelo de resistência à penetração para a posição DT:

$$
R P=0,0235 \cdot \theta^{3,8539} \cdot D_{s}^{1,6906}
$$

Modelo de resistência à penetração para a posição ET:

$$
R P=0,0278 * \theta^{-3,8539} \cdot D_{s}^{1,6006}
$$

Os valores da Tabela 4 demonstram que a posição influenciou significativamente a RP. O menor valor do intercepto na equação (6) $(\alpha=0,0235)$ que na equação $(7)(d=0,0278)$ indica que, para valores iguais de umidade e densidade do solo nas posições DT e ET, a resistência do solo à 
penetração das raizes é menor debaixo das touceiras. Isto implica num ambiente mais favorável ao desenvolvimento radicular.

As equações (6) e (7) foram utilizadas para determinar se existem condições restritivas ao crescimento radicular nas posições DT e ET, considerando o conteúdo de água no solo que corresponde ao potencial mátrico $(\psi)$ de 0,08 MPa. Este dato foi obtido de Moraes et al. (1993) e corresponde a um valor de $\theta=0,349 \mathrm{~cm}^{3} \mathrm{~cm}^{-3}$.

A distribuição espacial dos valores de resistência à penetração determinados com o modelo, para as posições estudadas, é apresentada na Figura 4, a qual foi feita com o "software" Origin da Microcal Software, Inc. (1997). A imagem superior da figura foi obtida interpolando os 24 valores de resistência à penetração para a posição ET, enquanto que para a imagem inferior foram empregados os 24 valores da posição DT. A interpolação foi efetuada utilizando o método de Kriging (Davis, 1986).

A representação tridimensional dos valores de resistência à penetração mostra que o solo entre as touceiras apresenta valores restritivos para o desenvolvimento radicular, distribuídos uniformemente em toda a área. Entretanto, os valores de RP debaixo das touceiras sugerem condições não limitantes para o crescimento das raizes, igualmente distribuidos em toda a área. Os resultados neste estudo indicam que na área amostrada há uma distribuição espacial da resistência diferenciada nas posições entre e sob as plantas. A maior RP na posição ET pode estar influenciando o crescimento do sistema radicular do capim-elefante em virtude de ocorrer em niveis considerados restritivos com o secamento do solo.

Reduções elevadas das taxas de elongação radicular foram assinaladas por Gupta \& Allmaras (1987) e Vepraskas (1994) quando a RP supera o valor de $2,5 \mathrm{MPa}$, o qual foi considerado como limitante ao desenvolvimento das raízes. Atwell (1993) determinou que valores de RP 
considerados limitantes podem diminuir num 50\% a taxa de elongação radicular de várias espécies de interesse agronômico (milho, trigo, algodão).

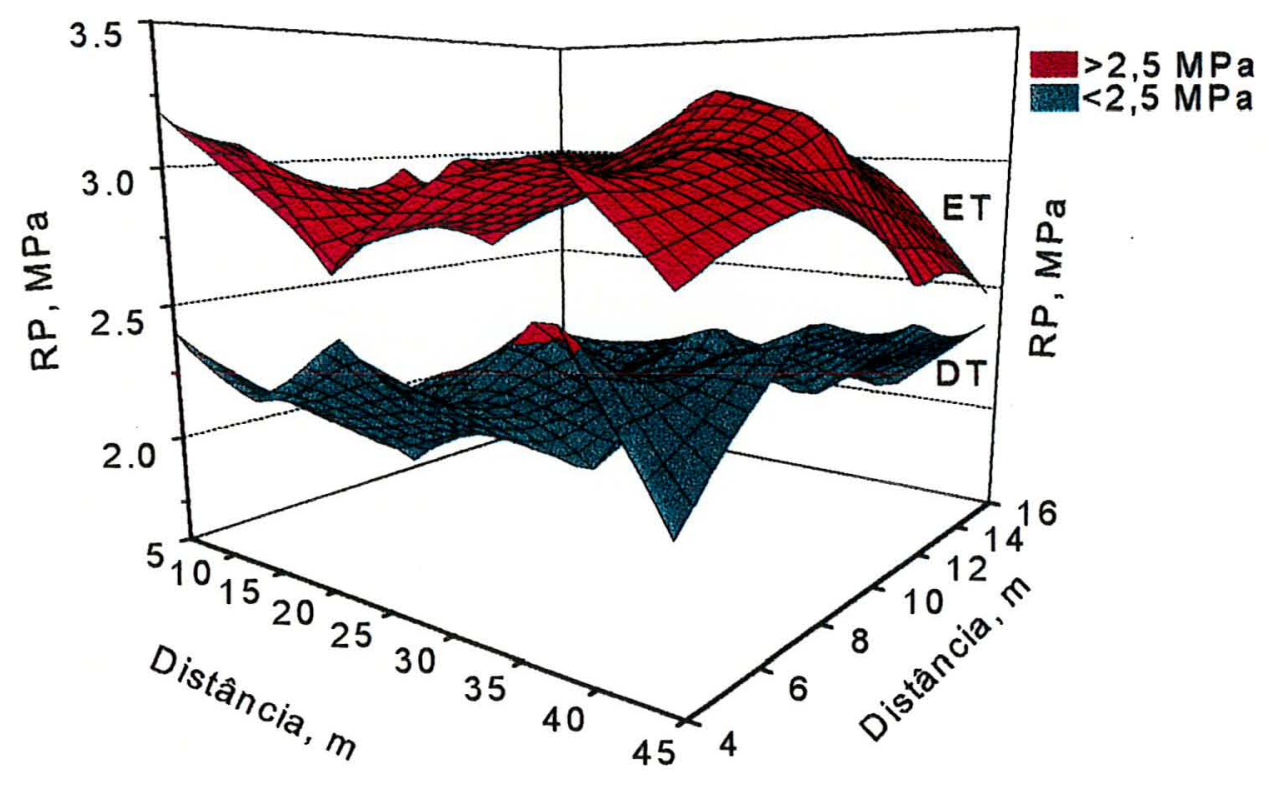

Figura 4 - Representação tridimensional dos valores de resistência à penetração, debaixo das touceiras e entre as touceiras, no sistema de pastejo rotacionado intensivo.

Os resultados de Ds e RP indicaram que existe heterogeneidade espacial dessas propriedades físicas no solo, a qual pode ter sido induzida pelo pisoteio animal. Essa variabilidade ocorre num espaço reduzido, correspondendo às posições espaciais debaixo das touceiras e entre as touceiras. Schlesinger et al. (1996) também concluíram que a heterogeneidade espacial induzida pelas forrageiras perenes ocorre a nível de pequenas distâncias (menor que $20 \mathrm{~cm}$ ). A variabilidade espacial verificada para esses atributos físicos, com valores de resistência à penetração restritivos ao 
desenvolvimento radicular, sugerem a existência de "ilhas de fertilidade física" no sistema estudado. Estes resultados indicam um zoneamento espacial do perfil em relação às condições físicas para o crescimento das raízes em que condições mais favoráveis poderiam confinar as raizes no local imediatamente abaixo das touceiras.

A presença de "ilhas de fertilidade física" exige que, durante o seu desenvolvimento, as plantas integrem essa variabilidade. A heterogeneidade espacial da resistência mecânica do solo e de outros atributos físicos, tais como a aeração, a temperatura do solo, a disponibilidade de água e nutrientes, condicionam o desenvolvimento do sistema radicular. Segundo Boone \& Veen (1994) quando a variabilidade espacial é maior que a extensão do sistema radicular, a posição relativa das plantas em relação a essa variabilidade determina as possibilidades de crescimento do sistema radicular, e a produção de biomassa total.

As plantas que crescem com o seu sistema radicular em condições físicas restritivas parecem ter capacidade de identificar essas condições e enviar um sinal, provavelmente de tipo hormonal, para a parte aérea. Nessas condiçōes o resultado é uma redução na taxa de expansão foliar (Blackman \& Davies, 1985; Blum et al. 1991; Masle \& Passioura, 1987; Passioura, 1988a; Passioura, 1991b; Saab \& Sharp, 1989). Como conseqüência, a produção de biomassa aérea diminui e é, quase sempre, mais afetada que a produção de matéria seca das raízes. Masle \& Passioura (1987) assinalaram que a relação área foliar/peso total de plantas de trigo é diminuida quando a resistência à penetração atinge valores próximos de $3 \mathrm{MPa}$. Esses resultados sugerem que propriedades físicas restritivas ao crescimento das raízes podem comprometer severamente a produtividade potencial das pastagens, nas quais a produção de folhas é o fator chave da sustentabilidade do sistema pecuário.

A heterogeneidade do solo e a natureza persistente das condições impeditivas ao desenvolvimento radicular, que refletem na produtividade total, 
exigem avaliações detalhadas para compreender como as condições físicas restritivas se distribuem ao redor das raízes nos mais variados tipos de solos. Os resultados deste estudo indicam que no solo, sob pastagem, há uma grande variabilidade nos atributos físicos os quais, provavelmente, impõem limitações ao crescimento das raizes. Pesquisas mais conclusivas que permitam identificar, para os atributos do solo, os limites críticos a partir dos quais a produção da pastagem começa a ser reduzida, são necessárias. Técnicas de geoestatistica poderiam ser utilizadas para melhor descrever a heterogeneidade desses atributos. 


\section{CONCLUSÕES}

No sistema de pastejo rotacionado intensivo estudado:

Não existem diferenças significativas nos atributos químicos do solo associados com as áreas sob e entre as plantas de capim-elefante.

As propriedades físicas foram alteradas de forma diferenciada nas posições espaciais debaixo das touceiras e entre as touceiras. Não foram determinadas diferenças estatísticas significativas para o diâmetro médio geométrico dos agregados, quando comparadas as duas posições. Entretanto, a densidade do solo e a resistência mecânica do solo foram significativamente mais elevadas entre as touceiras que sob as touceiras.

A heterogeneidade espacial da densidade do solo e da resistência à penetração do solo ocorreu no nível de escala pequena, visto que está associada à presença de plantas e solo descoberto.

Os resultados indicam, conforme a análise estatística utilizada, a ausência de "ilhas de fertilidade química", enquanto sugerem a existência de "ilhas de fertilidade física" para os atributos densidade do solo e resistência mecânica do solo. 


\section{REFERÊNCIAS BIBLIOGRÁFICAS}

AGUIAR, A. Possibilidades de intensificação do uso da pastagem através de rotação sem e com uso mínimo de fertilizantes. In: FUNDAMENTOS DO PASTEJO ROTACIONADO, Piracicaba, 1997. Anais. Piracicaba, FEALQ, 1997. p.85-138.

ATWELL, B.J. Response of roots to mechanical impedance. Environmental and Experimental Botany, v.33, n.1, p.27-40, 1993.

BARBER, S.A. Soil nutrient bioavailability. A mechanistic approach. New York: Jhon Wiley \& Sons, 1984. 398p.

BENGOUGH, A.G. The penetrometer in relation to mechanical resistance to root growth. In: SMITH, K.; MULLINS, C. Soil analysis: physical methods. New York: M. Dekker, 1991. cap.10, p.431-445.

BENGOUGH, A.G.; CROSER, C.; PRITCHARD, J. A biophysical analysis of root growth under mechanical stress. Plant and Soil, v.189, n.1, p.155164, 1997.

BENNIE, A.T.P. Growth and mechanical impedance. In: WAISEL, Y.; ESHEL, A.; KAFKAFI, U. (Ed) Plant roots: the hidden half. New York: $M$. Dekker, 1991. cap.19, p.393-414.

BLACKMAN, P.G.; DAVIES, W.J. Root to shoot communication in maize plants of the effects of soil drying. Journal of Experimental Botany, v.36, n. 162, p.39-48, 1985.

BLAKE, G.R.; HARTGE, K.H. Bulk density. In: KLUTE,A.(Ed.) Methods of soil analysis: physical and mineralogical methods. Madison: American Society of Agronomy, 1986. p.363-375. 
BLUM, A.; JOHNSON, J.W.; RAMSEUR, E.L.; TOLLNER, E.W. The effect of a drying top soil and a possible non-hydraulic root signal on wheat growth and yield. Journal of Experimental Botany, v.42, n.243, p.1225-1231, 1991.

BOONE, F.R.; VEEN, B.W. Mechanisms of crop responses to soil compaction. In: SOANE, B.D.; OUWERKERK, C. VAN. (Ed.). Soil compaction in crop production. Amsterdam: Elsevier, 1994. cap.11, p.237-264.

BRAUNACK, M.V.; DEXTER, A.R. Soil aggregation in the seedbed: a review. I. properties of aggregates and beds of aggregates. Soil and Tillage Research, v.14, n.3, p.259-279, 1989a.

BRAUNACK, M.V.; DEXTER, A.R. Soil aggregation in the seedbed: a review. II. Effect of aggregate sizes on plant growth. Soil and Tillage Research, v.14, n.3, p.281-298, 1989b.

BURKE, I.C.; LAUENROTH, W.K.; PARTON, W.J. Regional and temporal variation in net primary production and nitrogen mineralization in grasslands. Ecology, v.78, n.5, p.1330-1340, 1997.

BUSSCHER, W.J. Adjustment of flat-tipped penetrometer resistance data to a common water content. American Society of Agricultural Engineers, v.3, n.2, p.519-524. 1990.

CARVALHO, S.R. Influência de dois sistemas de manejo de pastagens na compactação de uma Terra Roxa estruturada. Piracicaba, 1976. 89p. Dissertação (Mestrado) - Escola Superior de Agricultura "Luiz de Queiroz", Universidade de São Paulo.

CORRECHEL, V. Densidade do solo: influência da posição relativa à linha de plantio em dois sistemas de preparo do solo. Piracicaba, 1998. 41p. Dissertação (Mestrado) - Escola Superior de Agricultura "Luiz de Queiroz", Universidade de São Paulo.

CORSI, M.; MARTHA JÚNIOR, G. Manutenção da fertilidade do solo em sistemas de pastejo rotacionado. In: FUNDAMENTOS DO PASTEJO 
ROTACIONADO, Piracicaba, 1997. Anais. Piracicaba: FEALQ, 1997. p.161-192.

DARWISH, O.H.; PERSAUD, N.; MARTENS, D.C. Effect of long-term application of animal manure on physical properties of three soils. Plant and Soil, v.176, n.2, p.289-295, 1995.

DAVIES, A.; ADAMS, W. A.; WILMAN, D. Soil compaction in permanent pasture and its amelioration by slitting. Journal of Agricultural Science, v.113, n.2, p.189-197, 1989.

DAVIS, J.C. Statistics and data analysis in geology. 2 ed. New York: J. Wiley \& Sons, 1986. 383p.

DEGENS, B.P. Macro-aggregation of soils by biological bonding and binding mechanisms and factors affecting these: a review. Australian Journal of Soil Research, v.35, n.1, p.431-459, 1997.

DERNER, J.D; BRISKE, D.D.; BOUTTON, T.W. Does grazing mediate soil carbon and nitrogen accumulation beneath $\mathrm{C}_{4}$, perennial grasses along an environmental gradient? Plant and Soil, v.191, n.2, p.147-156, 1997.

DEXTER, A.R. Advances in characterization of soil structure. Soil and Tillage Research, v.11, n.3-4, p.199-238, 1988.

DEXTER, A.R. Physical properties of tilled soils. Soil and Tillage Research, v.43, n.1-2, p.41-63, 1997.

DONALD, R.G.; KAY, B.D.; MILLER, M.H. The effect of soil aggregate size on early shoot and root growth of maize (Zea mays L.). Plant and Soil, v.103, n.2, p.251-259, 1987.

DORMAAR, J.F; SMOLIAK, S.; WILLMS, W.F Vegetation and soil responses to short-duration grazing on fescue grasslands. Journal of Range Management, v.42, n.3, p.252-256, 1989.

DOUGLAS, J.T. Responses of perennial forage crops to soil compaction. In: SOANE, B.D.; OUWERKERK, C. VAN. (Ed.). Soil compaction in crop production. Amsterdam: Elsevier, 1994. cap 15, p.343-364. 
EPSTEIN, H.E.; LAUENROTH, W.K.; BURKE, I.C; COFFIN, D.P. Productivity patterns of $\mathrm{C}_{3}$ and $\mathrm{C}_{4}$ functional types in the U.S. great plains. Ecology, v.78, n.3, p.722-731, 1997.

FARIA, V.P. de; SILVA, S.C. da; CORSI, M. Potencial e perspectivas do pastejo em capim elefante. In: PEIXOTO, A.M.; MOURA, J.C. de; FARIA, V.P. de (Ed.). Pastagens de capim elefante, utilizaçăo intensiva. Piracicaba: FEALQ, 1996. p.7-27.

GIJSMAN, A.J.; THOMAS, R.J. Evaluation of some physical properties of an oxisol after conversion of native savanna into legume-based or pure grass pastures. Tropical Grasslands, v.30, n.2, p.237-248, 1996.

GLINSKI, J.; LIPIEC, J. Soil physical conditions and plant roots. Florida: CRC Press, 1990. 250p.

GOSS, M.J. The specific effects of roots on the regeneration of soil structure. In: MONNIER, G.; GOSS, M.J. (Ed.). Soil compaction and regeneration. Netherlands: A. A. Balkema, 1987. p.145-155.

GUPTA, S.C.; SHARMA, P.P.; DEFRANCHI, S.A. Compaction effects on soil structure. Advances in Agronomy, v.42, p.311-338. 1989.

GUPTA, S.C.; ALLMARAS, R.R. Models to assess the susceptibility of soils to excessive compaction. Advances in Soil Science, v.6, p.65-100, 1987.

HADAS, A. Soil tilth - the desired soil structural state obtained through proper soil fragmentation and reorientation processes. Soil and Tillage Research, v.43, n.1-2, p.7-40, 1997.

HARRISON, D.F.; CAMERON, K.C.; MCLAREN, R.G. Effects of subsoil loosening on soil physical properties, plant root growth, and pasture yield. New Zealand Journal of Agricultural Research, v.37, n.4, p.559-567, 1994.

HAVEREN, B.B. VAN. Soil bulk density as influenced by grazing intensity and soil type on a shortgrass prairie site. Journal of Range Management, v.36, n.5, p.586-588, 1983. 
HAYNES, R.J.; WILLIAMS, P.H. Nutrient cycling and soil fertility in the grazed pasture ecosystem. Advances in Agronomy, v.49, p.119-199, 1993.

HETTIARATCHI, D.R.P. The mechanics of soil-root interactions. In: WAGENET, R.J.; BAVEYE, P.; STEWART, B.A. (Ed.). Interacting processes in soil science. Boca Raton: Lewis Publishers, 1992. p.255288.

HILLESHEIM, A. Fatores que afetam o consumo e perdas de capim-elefante (pennisetum purpureum, Schum.) sob pastejo. Piracicaba, 1987. 94p. Dissertação (Mestrado) - Escola Superior de Agricultura "Luiz de Queiroz", Universidade de São Paulo.

HOFFMANN, C.; JUNGK, A. Growth and phosphorus supply of sugar beet as affected by soil compaction and water tension. Plant and Soil, v.176, n.1, p.15-25, 1995.

HOOK, P.B; BURKE, I.C.; LAUENROTH, W.K. Heterogeneity of soil and plant $\mathrm{N}$ and $\mathrm{C}$ associated with individual plants and openings in North American shortgrass steppe. Plant and Soil, v. 138, n.1, p. 247-256, 1991.

HORN, R.; LEBERT, M. Soil compactability and compressibility. In: SOANE, B.D.; OUWERKERK, C. VAN. (Ed.). Soil compaction in crop production. Amsterdam: Elsevier, 1994. cap 3, p.45-69.

HORN, R.; TAUBNER, H.; WUTTKE, M.; BAUMGARTL, T. Soil physical properties related to soil structure. Soil and Tillage Research, v.30, n.24, p.187-216, 1994.

HORN, R.; DOMZAL, H.; SLOWINSKA-JURKIEWICZ, A.; OUWERKERK, C.VAN. Soil compaction processes and their effects on the structure of arable soils and the environment. Soil and Tillage Research, v.35, n.1, p.23-36, 1995.

JACKSON, R.B.; CALDWELL, M.M. The timing and degree of root proliferation in fertile-soil microsites for three cold-desert perennials. Oecologia, v.81, n.2, p.149-153, 1989. 
JACKSON, R.B; CALDWELL, M.M. The scale of nutrient heterogeneity around individual plants and its quantification with geostatistics. Ecology, v.74, n.2, p.612-614, 1993.

KELLY, R.H; BURKE, I.C. Heterogeneity of soil organic matter following death of individual plants in shortgrass steppe. Ecology, v.78, n.4, p.1256-1261, 1997.

KELLY, R.H; BURKE, I.C; LAUENROTH, W.K. Soil organic matter and nutrient availability responses to reduced plant inputs in shortgrass steppe. Ecology, v.77, n.8, p.2516-2527, 1996.

KICHEL, A.N.; MIRANDA, C.H.B.; ZIMMER, A.H. Fatores de degradação de pastagem sob pastejo rotacionado com ênfase na fase de implantação. In: FUNDAMENTOS DO PASTEJO ROTACIONADO, Piracicaba, 1997. Anais. Piracicaba: FEALQ, 1997. p.193-212.

KLUTE, A. Water retention: laboratory methods. In: KLUTE, A. Methods of soil analysis. Part 1, Physical and mineralogical methods, 2 ed., Madison: SSSA, 1986. cap.26, p.635-660.

LETEY, J. Relationship between soil physical properties and crop production. Advances in Soil Science, v.1, p.277-294, 1985.

LIPIEC, J.; STEPNIEWSKI, W. Effects of soil compaction and tillage systems on uptake and losses of nutrients. Soil and Tillage Research, v.35, n.1-2, p.37-52, 1995.

MANLEY, J.T; SCHUMAN, G.E.; REEDER, J.D.; HART, R.H. Rangeland soil carbon and nitrogen responses to grazing. Journal of Soil and Water Conservation, v.50, n.3, p.294-298, 1995.

MARSCHNER, H. Mineral nutrition of higher plants. 2.ed. London: Academic Press, 1995. 889p.

MARSHALL, T.J.; HOLMES, J.W.; ROSE, C.W. Soil physics. 3.ed. Cambridge: Cambridge University Press, 1996. 453p. 
MASLE, J.; PASSIOURA, J.B. The effect of soil strength on the growth of young wheat plants. Australian Journal of Plant Physiology, v.14, n.6, p.643656, 1987.

MEAD, J.A.; CHAN, K.Y. Cultivation techniques and grazing affect surface structure of an Australian hardsetting soil. Soil and Tillage Research, v.25, n.2-3, p.217-230, 1992.

MONTEIRO, F.A.; WERNER, J.C. Reciclagem de nutrientes em pastagens. In: FUNDAMENTOS DO PASTEJO ROTACIONADO, Piracicaba, 1997. Anais. Piracicaba: FEALQ, 1997. p.55-84.

MORAES, S.Q.; LIBARDI, P.L.; NETO, D.D. Problemas metodológicos na obtenção da curva de retenção da água pelo solo. Scientia Agricola, v.50, n.3, p.383-392, 1993.

MURPHY, W.M.; BARRETO, A.D.; SILMAN, J.P.; DINDAL, D.L. Cattle and sheep grazing effects on soil organisms, fertility and compaction in a smooth-stalked meadowgrass-dominant white clover sward. Grass and Forrage Science, v.50, n.3, p.191-194, 1995.

OADES, J.M. Soil organic matter and structural stability: mechanisms and implications for management. Plant and Soil, v.76, n.1-3, p.319-337, 1984.

OMETTO, J.C. Registros e estimativas de parâmetros metereológicos da região de Piracicaba, S.P. Piracicaba: FEALQ, 1989. 76p.

MICROCAL SOFTWARE. Data analysis and technical graphics. 3D and contour manual. Version 5. Northampton: Microcal Software, 1997. 61p.

PASSIOURA, J.B. Root signals control leaf expansion in wheat seedlings growing in drying soil. Australian Journal of Plant Physiology, v.15, p.687-693, 1988a.

PASSIOURA, J.B. Soil structure and plant growth. Australian Journal of Soil Research, v.29, n.6, p.717-728, 1991b.

PERFECT, E.; KAY, B.D.; FERGUSON, J.A.; SILVA, A.P.da; DENHOLM, K.A. Comparison of functions for characterizing the dry aggregate size 
distribution of tilled soil. Soil and Tillage Research, v.28, n.1-2, p.123139, 1993.

PREVEDELLO, B.M.S. Variabilidade espacial de parâmetros de solo e planta. Piracicaba, 1987. 166p. Tese de Doutorado - Escola Superior de Agricultura "Luiz de Queiroz", Universidade de São Paulo.

PROFFITT, A.P.B; BENDOTTI, S.; HOWELL, M.R.; EASTHAM, J. The effect of sheep trampling and grazing on soil physical properties and pasture growth for a Red-Brown earth. Australian Journal of Agricultural Research, v.44, n.2, p.317-331, 1993.

PROFFITT, A.P.B.; BENDOTTI, S.; MCGARRY, D. A comparison between continuous and controlled grazing on a red duplex soil. I. Effects on soil physical characteristics. Soil and Tillage Research, v.35, n.4, p.199-210, 1995.

RAIJ, B. VAN; QUAGGIO, J.A ; CANTARELLA, H.; FERREIRA, M.E.; LOPES, A.S.; BATAGLIA, O.C. Análise química do solo para fins de fertilidade. Campinas: Fundação Cargill, 1987. 170p.

RAIJ, B. VAN; CANTARELLA, H.; QUAGGIO, J.A.; FURLANI, A.M.C. Recomendações de adubação e calagem para o Estado de São Paulo. 2.ed. Campinas: Instituto Agronômico e Fundação IAC, 1996. 285p.

RENDIG, V.V.; TAYLOR, H.M. Principles of soil-plant interrelationships. New York: McGraw-Hill Publis., 1989. 275p.

REZENDE, J. de O. Compactação e adensamento do solo: métodos para avaliação e práticas agrícolas recomendadas (compact disc). In: CONGRESSO BRASILEIRO DE CIÊNCIA DO SOLO, 25., Rio de Janeiro, 1997. Palestra. SBCS, 1997.

ROBINSON, D. The responses of plants to non-uniform supplies of nutrients. New Phytologist, v.127, n.4, p.635-674, 1994.

RODRIGUES, L.R. de A.; REIS, R.A. Conceituação e modalidade de sistemas intensivos de pastejo rotacionado. In: FUNDAMENTOS DO PASTEJO 
ROTACIONADO, Piracicaba, 1997. Anais. Piracicaba: FEALQ, 1997. p.1-23.

RODRIGUES, L.R. de A.; RODRIGUES, T. de J.D. Ecofisiologia de plantas forrageiras. In: CASTRO, P.R.C.; FERREIRA, S.O; YAMADA, T. (Ed.). Ecofisiologia da produção agrícola. Piracicaba: Associação Brasileira para Pesquisa da Potassa e do Fosfato, 1987. cap 12, p.203-230.

RODRIGUEZ, J. Manual de fertilización. Santiago: Facultad de Agronomía Pontificia Universidad Católica de Chile, 1993. 362p.

ROLIM, F. de A. Estacionalidade de produção de forrageiras. In: PEIXOTO, A.M.; MOURA, J.C.DE; FARIA, V.P.DE. Pastagens: fundamentos da exploração racional. Piracicaba: FEALQ, 1986. p.243-270.

RUSSELL, R.S. Plant root systems: their function and interaction with the soil. London: McGraw-Hill Book, 1977. 298p.

SAAB, I.N.; SHARP, R.E. Non-hydraulic signals from maize roots in dryng soil: inhibition of leaf elongation but not stomatal conductance. Planta, v.179, n.4, p.466-474, 1989.

SANTOS, F.A.P. Manejo de pastagens de capim elefante. In: SANTOS, F.A.P.; NUSSIO, L.G.; SILVA, S.C. Volumosos para bovinos. Piracicaba: FEALQ, 1993. p.1-20.

SAUNDERS, W.M.H. Mineral composition of soil and pasture from areas of grazed paddocks, affected and unaffected by dung and urine. New Zealand Journal of Agricultural Research, v.27, n.3, p.405-412, 1984.

SCHLESINGER, W.H; REYNOLDS, J.F; CUNNINGHAM, G.L; HUENNEKE, L.F; JARRELL, W.M; VIRGINIA, R.A.; WHITFORD, W.G Biological feedback's in global desertification. Science, v.247, n.4946, p.1043-1047, 1990.

SCHLESINGER, W.H; RAIKES, J.A.; HARTLEY, A.E.; CROSS, A.F. On the spatial pattern of soil nutrients in desert ecosystems. Ecology, v.77, n.2, p.364-374, 1996. 
SCHOLEFIELD, D.; PATTO, P.M.; HALL, D.M. Laboratory research on the compressibility of four topsoils from grasslands. Soil and Tillage Research, v.6, n.1, p.1-16, 1985.

SHIERLAW, J.; ALSTON, A.M. Effect of soil compaction on root growth and uptake of phosphorus. Plant and Soil, v.77, n.1, p.15-28, 1984.

SEMMEL, H.; HORN, R.; HELL, U.; DEXTER, A.R.; SCHULZE, E.D. The dynamics of soil aggregate formation and the effect on soil physical properties. Soil Technology, v.3,n.1, p.113-129, 1990.

SILVA, A. P. da; TORMENA, C.A.; MAZZA, J.A. Manejo físico de solos sob pastagem. In: FUNDAMENTOS DO PASTEJO ROTACIONADO, Piracicaba, 1997. Anais. Piracicaba: FEALQ, 1997a. p.25-39.

SILVA, A. P. da; KAY, B.D.; PERFECT, E. Management versus inherent soil properties effects on bulk density and relative compaction. Soil and Tillage Research, v.44. p.81-93, 1997b.

SILVA, S.C.; FARIA, V.; CORSI, M. Sistema intensivo de produção de leite em pastagens de capim elefante do Departamento de Zootecnia da ESALQ. In: $2^{\circ}$ CONGRESSO BRASILEIRO DE GADO LEITEIRO, Piracicaba, 1996. Anais Piracicaba: FEALQ, 1996. p.97-122.

SOANE, B.D.; OUWERKERK, C. VAN. Implications of soil compaction in crop production for the quality of the environment. Soil and Tillage Research, v.35, n.1-2, p.5-22, 1995.

STATISTICAL ANALYSIS SYSTEM INSTITUTE. SAS/STAT Procedure guide for personal computers. Version 5, SAS Inst. Cary, NC. 1991.

STEPHENSON, G.R.; VEIGEL, A. Recovery of compacted soil on pastures used for winter cattle feeding. Journal of Range Management, v.40, n.1, p.46-48, 1987.

TANNER, C.B.; MAMARIL, C.P. Pasture soil compaction by animal traffic. Agronomy Journal, v.51, n.6, p.329-331, 1959. 
TARDIEU, F. Growth and functioning of roots and fo root systems subjected to soil compaction. Towards a system with multiple signaling. Soil and Tillage Research, v.30, n.2-4, p.217-243, 1994.

TAYLOR, H.M.; BURNETT, E. Influence of soil strength on root growth habits of plants. Soil Science, v.98, n.3, p.174-180, 1964.

TISDALL, J.M.; OADES, J.M. Organic matter and water-stable aggregate in soils. Journal of Soil Science, v.33, n.2, p.141-163, 1982.

UNGER, P.W.; KASPAR, T.C. Soil compaction and root growth: a review. Agronomy Journal, v.86, n.5, p.759-766, 1994.

VEPRASKAS, M.J. Plant response mechanisms to soil compaction. In: WILKINSON, R. (Ed.) Plant environment interactions. New York: Books in soils, Plant and the environment, 1994. cap.9, p. 263-287.

VINTON, M.A.; BURKE, I.C. Interactions between individual plant species and soil nutrient status in shortgrass steppe. Ecology, v.76, n.4, p.1116-1133, 1995.

WARREN, S.D.; BLACKBURN, W.H.; TAYLOR, C.A. Effects of season and stage of rotation cycle on hydrologic condition of rangeland under intensive rotation grazing. Journal of Range Management, v.39, n.6, p.486-491, $1986 a$.

WARREN, S.D.; NEVILL, M.B.; BLACKBURN, W.H.; GARZA, N.E. Soil response to trampling under intensive rotation grazing. Soil Science Society of America Journal, v.50, n.5, p.1336-1341, 1986b.

WHITE, W.M. Dry aggregate distribution. In: CARTER, M.R. (Ed.). Soil Sampling and Methods of Analysis. Canada: Lewis Publis., 1993. P.659-662.

WILLATT, S.T; PULLAR, D.M. Changes in soil physical properties under grazed pastures. Australian Journal of Soil Research, v.22, n.4, p.343-348, 1983. 
WOOD, M.K.; BLACKBURN, W.H. Vegetation and soil responses to cattle grazing systems in the Texas Rolling Plains. Journal of Range Management, v.37, n.4, p.303-308, 1984. 